\title{
An integrative view of mammalian seasonal neuroendocrinology
}

\author{
Hugues Dardente ${ }^{1}$ (D) | Shona Wood ${ }^{2}$ (D) | Francis Ebling ${ }^{3}$ (D) | Cristina Sáenz de Miera ${ }^{4}$
}

${ }^{1}$ Physiologie de la Reproduction et des Comportements, INRA, CNRS, IFCE, Université de Tours, Nouzilly, France

${ }^{2}$ Department of Arctic and Marine Biology, The Arctic University of Norway, Tromsø, Norway

${ }^{3}$ School of Life Sciences, University of Nottingham, Nottingham, UK

${ }^{4}$ Molecular and Integrative

Physiology, University of Michigan, Ann Arbor, Michigan

\section{Correspondence}

Cristina Sáenz de Miera, Department of Molecular and Integrative Physiology, The University of Michigan, Ann Arbor, MI. Email: cristinasaenzdemiera@gmail.com

\begin{abstract}
Seasonal neuroendocrine cycles that govern annual changes in reproductive activity, energy metabolism and hair growth are almost ubiquitous in mammals that have evolved at temperate and polar latitudes. Changes in nocturnal melatonin secretion regulating gene expression in the pars tuberalis (PT) of the pituitary stalk are a critical common feature in seasonal mammals. The PT sends signal(s) to the pars distalis of the pituitary to regulate prolactin secretion and thus the annual moult cycle. The PT also signals in a retrograde manner via thyroid-stimulating hormone to tanycytes, which line the ventral wall of the third ventricle in the hypothalamus. Tanycytes show seasonal plasticity in gene expression and play a pivotal role in regulating local thyroid hormone $(\mathrm{TH})$ availability. Within the mediobasal hypothalamus, the cellular and molecular targets of TH remain elusive. However, two populations of hypothalamic neurones, which produce the RF-amide neuropeptides kisspeptin and RFRP3 (RFamide related peptide 3 ), are plausible relays between $\mathrm{TH}$ and the gonadotrophinreleasing hormone-pituitary-gonadal axis. By contrast, the ways by which $\mathrm{TH}$ also impinges on hypothalamic systems regulating energy intake and expenditure remain unknown. Here, we review the neuroendocrine underpinnings of seasonality and identify several areas that warrant further research.
\end{abstract}

\section{KEYWORDS}

melatonin, pars tuberalis, photoperiod, seasonal remodelling, tanycytes, thyroid hormone

\section{1 | INTRODUCTION}

Daily and seasonal cycles have shaped the evolution of life on Earth. Migration, hibernation, aestivation, diapause, pelage moult, reproductive status and changing ingestive behaviour are all examples of key adaptive strategies that have been implemented in a species-specific manner. These strategies ensure an optimal temporal use of a diversity of environmental niches. The underlying processes, which include extensive morphological, physiological and behavioural changes, typically take weeks to months to complete. Therefore, the ability to keep track of the time of year to anticipate upcoming changes is crucial. The annual change in day length (photoperiod) is the most predictive signal (noise-free) for these seasonal changes, and so this has been selected as the main driver of seasonal programmes in most species living at temperate and polar latitudes. Animals have evolved to use changes in photoperiod in concert with endogenous long-term timers, known as circannual clocks, to synchronise seasonal functions.

The underlying central cellular and molecular mechanisms governing seasonality and circannual timing are still poorly understood. However, recent advances have highlighted a conserved neuroendocrine pathway across vertebrates. This pathway, as well as its molecular components, is involved in photoperiod measurement and might also be an integral part of the elusive circannual clock. The aim of this review is to summarise our current understanding of the mechanisms that underlie mammalian seasonality, providing 


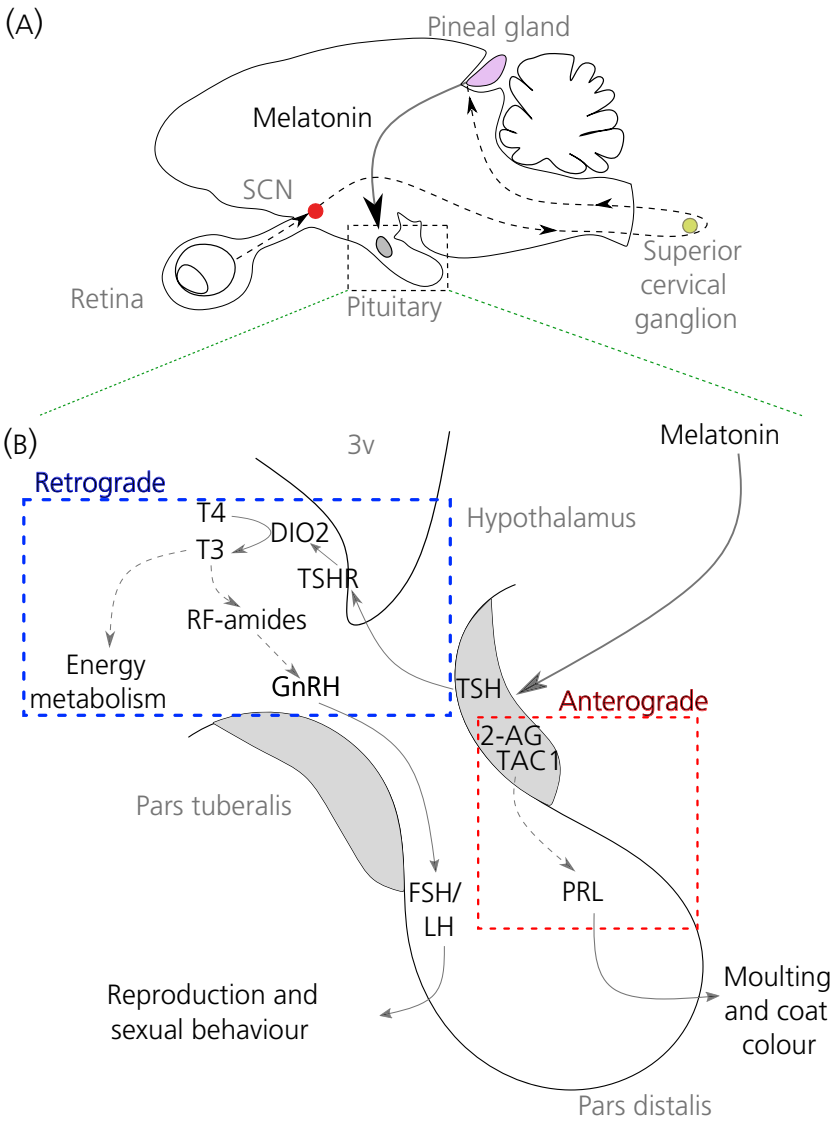

FIGURE 1 Neuroendocrine pathways of seasonality. A, In mammals, the photic input pathway from the retina to the suprachiasmatic nuclei ( $\mathrm{SCN}$ ) drives rhythmic melatonin production from the pineal gland. This melatonin signal provides an internal endocrine representation for external photoperiod. Short (winter) photoperiods are represented by increased duration of melatonin and long (summer) photoperiods by short duration of melatonin. $\mathrm{B}$, Retrograde action of thyroid-stimulating hormone (TSH) on ependymal cells in the hypothalamus (blue box). The prime site of melatonin action is the pituitary pars tuberalis. Pars tuberalis (PT)derived TSH is translocated back to the hypothalamus where it binds to TSH receptors (TSHR) expressed in tanycytes lining the third ventricle. This regulates the expression of deiodinases (Dio2 and Dio3), which in turn control the local metabolism of thyroid hormone (thyroxine [T4] to triiodothyronine [T3] conversion). Changes in T3 availability modulate energy metabolism and reproductive circuits. RF-amide peptides (ie, kisspeptin and RFRP3) likely serve as neuroendocrine intermediates in the regulation of reproduction. Anterograde action (red box) is believed to control seasonal prolactin (PRL) secretion from lactotrophic cells in the pars distalis, which drives the pelage/moult cycle. The pathway is stimulated through secretion of low molecular weight molecules (collectively termed "tuberalins") produced in the PT and transported to the pars distalis (PD) through the portal blood system. To date, several tuberalin candidates have been proposed including tachykinins (TAC1) and endocannabinoids (2-AG). 3V, third ventricle; FSH, follicle-stimulating hormone; GnRH, gonadotrophin-releasing hormone; $\mathrm{LH}$, luteinising hormone

a unique integrative view of research in multiple mammalian models to unravel commonalities and highlight open questions. We mostly focus on breeding and metabolic aspects of seasonal programmes because these have received particular attention. The current model (Figure 1) emphasises the role of thyroid-stimulating hormone (TSH) produced by the pars tuberalis (PT) of the pituitary in the seasonal control of thyroid hormone (TH) deiodinases (Dio2-Dio3) expressed in tanycytes and, in turn, TH levels within the neighbouring mediobasal hypothalamus (MBH) (Figure 1). We should emphasise that this molecular pathway appears to be conserved in a wide array of species, regardless of whether they are usually categorised as shortday breeders (exemplified by sheep) or long-day breeders (exemplified by hamsters and quail). Therefore, species-specific divergence downstream of this common pathway is anticipated, as highlighted recently by Helfer et al $^{1}$. Indeed, our understanding of downstream pathways, from triiodothyronine (T3) production to physiological seasonal outputs, remains limited. This undoubtedly constitutes the major unanswered question in the field, which should drive future research. Here, we further discuss the potential role of newly described "seasonal genes" that are expressed by the PT and tanycytes and consider how dynamic cellular and tissue-specific seasonal remodelling in the hypothalamus and pituitary might be implicated in seasonal timing. We also revisit the concept that control of luteinising hormone/follicle-stimulating hormone (LH/FSH) and prolactin (PRL) are likely governed in a coordinated manner by the PT, although with distinct pathways/messengers (retrograde vs anterograde) (Figure 1). Finally, we discuss recent findings on the roles of neuropeptides involved in seasonal metabolism and breeding. We focus on two neuropeptidergic systems involved in seasonal breeding: the family of kisspeptins (KP; encoded by the gene Kiss1), which are produced from proteolytic cleavage of a common precursor and only differ on the length of their N-term, and the RFRP3 neuropeptide (RF-amide related peptide 3 , encoded by the Npvf gene) (Figure 1).

\section{2 | PHOTOPERIODISM AND CIRCANNUAL RHYTHMICITY}

In mammals, duration of the nightly melatonin production by the pineal gland transduces the photoperiodic information to the body. ${ }^{2-6}$ Pineal gland removal (ie pinealectomy, PX) blocks both reproductive and metabolic responses to photoperiod in multiple species, including sheep and hamsters, ${ }^{7-9}$ whereas timed melatonin infusions in PX animals are sufficient to mimic photoperiodic responses. ${ }^{10-12}$

Endogenous long-term timers are coupled to photoperiod sensing, although there are marked differences in the nature and persistence of the endogenous rhythm, which led to the discrete categorisation of species as being either photoperiodic or circannual. Circannual species are defined by the persistence of full annual cycles of physiology in constant conditions. By contrast, photoperiodic species do exhibit endogenous rhythms, which represent only half an annual cycle. Small short-lived seasonal species such as Syrian and Siberian hamsters exemplify photoperiodic species: the activation of reproduction in spring takes place even though animals are maintained on a fixed short photoperiod (SP); it is independent from 

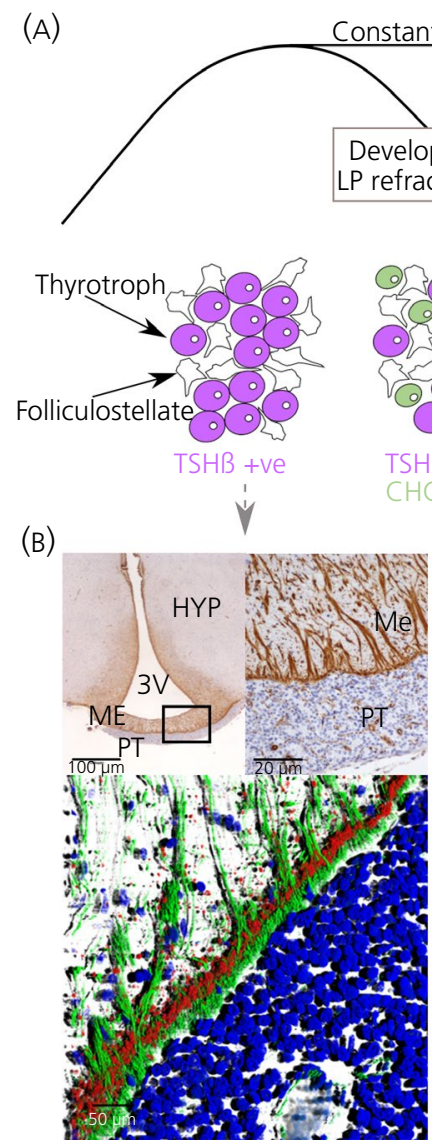

Reversion to winter phenotype
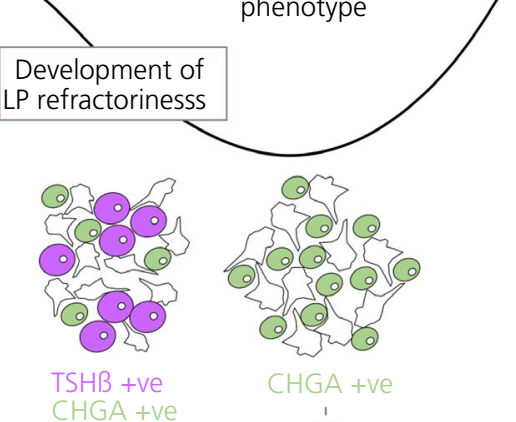
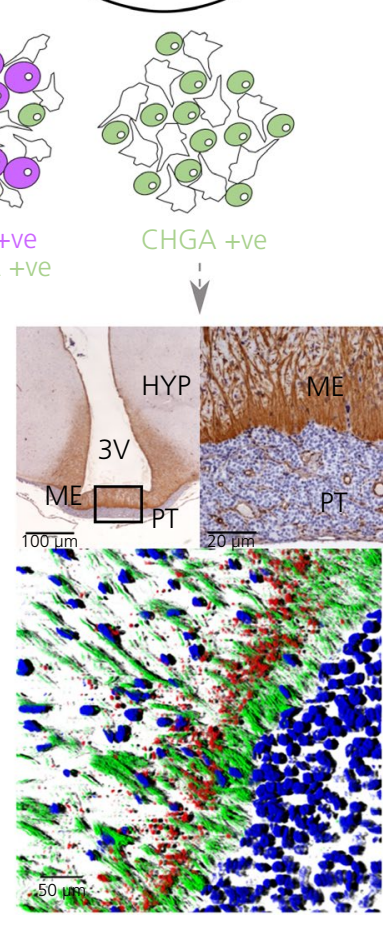

FIGURE 2 The binary switch model for pars tuberalis (PT) cells. A, The binary switch model proposes that an endogenous timer switches thyroid-stimulating hormone (TSH)B/EYA3 expression in the PT thyrotroph cells, driving TSH and hypothalamic thyroid hormone (TH) metabolism independently of photoperiod. Individual PT thyrotroph cells are either in a long (TSH/EYA3+) or short ( $\mathrm{CHGA}+$ ) photoperiod state, and the relative proportion of these binary-state cells determines the phase of the circannual cycle. Also shown are the cellular remodelling that occurs with season, thyrotrophs get bigger in summer and reorganise to increase junctional contacts. In winter, folliculostellate cells form a network with increased junctional contacts and thyrotrophs are isolated from each other. Adapted from Wood et al. ${ }^{41} \mathrm{~B}$, Vimentin immunostaining for tanycytes (brown) of coronal section of the sheep mediobasal hypothalamus (upper). Scale bar $=100$ and $20 \mu \mathrm{m}$, respectively. $3 \mathrm{~V}$, third ventricle; HYP, hypothalamus; ME, median eminence. 3D render series of immunohistochemistry images showing gonadotrophin-releasing hormone (GnRH) (red), vimentin (green) and 4',6-diamidino-2-phenylindole (blue) in short photoperiod (SP) and long photoperiod (LP). Scale bar $=50 \mu \mathrm{m}$. Adapted from Wood et al. ${ }^{41}$

increasing daylength, even though premature exposure to a long photoperiod (LP) triggers reproductive recrudescence. Therefore, initiation of the spring reproductive phenotype reflects refractoriness to the prevailing SP rather than LP activation, which is a hallmark of an endogenous timing device. However, reproductively active hamsters do not spontaneously revert to the reproductively inactive phenotype. This switch in physiology requires exposure to photoperiods with a duration shorter than the critical photoperiod

(approximately 12.5 hours $^{13}$ ). Refractory mechanisms are common to almost all seasonally breeding mammals which are sensitive to photoperiodic change, including marsupial lineages. ${ }^{14}$

By contrast, longer-lived species may display circannual cycles when maintained on a fixed photoperiod. In this case, animals display recurrent spontaneous switches to the opposite physiological status over time. These switches usually occur at rather stable time intervals even though the amplitude of the cycles dampens with time, depending on the species and the photoperiodic condition under which animals are maintained (Figure 2). Therefore, refractoriness occurs in both photoperiodic and circannual species, which suggest mechanistic similarities as detailed previously. ${ }^{3,6,15-17}$ The molecular and cellular substrates of this divergence (ie, the ability to show refractoriness only once or repeatedly over time) are unknown but we speculate they reflect varying degrees of "plasticity" in the neuroendocrine circuits downstream of photoperiod decoding, which in turn allow for differences in life history.

Circannual rhythms, an ancestral trait expressed in a large range of organisms, ${ }^{18}$ can persist for many cycles in constant conditions, even in the absence of a pineal gland, ${ }^{19,20}$ although these rhythms are no longer entrained to the solar year and depend on prior photoperiodic history. The importance of melatonin in endogenous rhythms has been questioned because the refractory state and/or circannual cycles occur without changes in the melatonin signal. ${ }^{21,22}$ However, in these cases, it is clear that the photoperiodic history of the animal has an effect. For example, in sheep and golden-mantled ground squirrels, a rhythmic melatonin signal is required for the generation of circannual rhythms, ${ }^{9,23}$ although this signal can be given for only 90 days (and in a summer-like melatonin profile) and still entrain the whole circannual cycle. In PX European hamsters, circannual rhythms persist under constant photoperiods ${ }^{24}$ and some PX animals can also entrain to a 6-month accelerated natural photoperiod cycle, ${ }^{25}$ arguing for independence of the circannual rhythm from melatonin. However, there is a clear season-dependent impact of PX, which suggests that photoperiodic history impacts the trajectory of the rhythms. Furthermore, the emergence of circannual rhythms appear to require prior exposure to LP and persistence of these rhythms is much more obvious when animals are housed under constant LP. ${ }^{26-29}$ Overall, exposure to LP appears to be both necessary and sufficient to prime then drive circannual cycles.

In a natural setting, the endogenous seasonal program is also manifested during the polar night and day and in response to equinoctial daylengths, which do not provide information regarding the direction of change. Here too, prior photoperiodic experience determines the appropriate biological response at each time of the year. $^{30,31}$ In arctic species, rhythmic melatonin secretion is halted during long periods around the summer and winter solstices. Despite this, the seasonal rhythms of these species remain synchronised to the sidereal year. ${ }^{32-35}$ These findings suggest that only part of the yearly photoperiodic information is meaningful to synchronise circannual rhythms, which is congruent with earlier observations in sheep. ${ }^{9}$ The impact of photoperiodic history on physiology has also been demonstrated in a developmental paradigm mimicking 
equinoctial responses in offspring. ${ }^{36-40}$ The trajectories of both reproductive and metabolic development drastically diverge according to the season of birth to ensure proper alignment of physiology with environmental constraints and opportunities. This phenotypic flexibility is set during gestation by maternal melatonin, which crosses the placental barrier to provide photoperiodic information to the foetuses. Importantly, this early photoperiodic history affects juvenile offspring's own photoperiodic interpretation demonstrating the 'programming' effect of maternal melatonin. ${ }^{36-40}$

\section{3 | SEASONALITY IN THE PT}

The PT and the hypothalamic tanycytes (specialised ependymal cells) are critical sites for integration of photoperiodic information and history and their transmission to neuroendocrine pathways controlling physiology. 5,17,20,26,41,42 In the search for neuroendocrine sites controlling seasonality, attention initially focused on the PT because it is the only consistent site of melatonin binding across a wide range of seasonally breeding mammalian species. ${ }^{43}$ Here, melatonin receptors are expressed in PT-specific thyrotrophs. ${ }^{44-46}$ In addition, the positioning of the PT, between the hypothalamus and the pituitary, in direct contact with the median eminence (ME), is ideal for coordinating both anterograde (towards the pars distalis of the pituitary, PD) and retrograde (back to the hypothalamus) pathways governing seasonal physiology. ${ }^{27}$ Similarly, endogenous circannual rhythms in PT-pituitary and PT-hypothalamic pathways keep on ticking in the absence of changing photoperiodic and melatonin conditions in seasonal mammals, leading to the proposal that the PT is pivotal to the generation of circannual rhythms. ${ }^{17,20,26}$

\section{4 | ANTEROGRADE SEASONAL REGULATION: FROM THE PT TO THE ANTERIOR PITUITARY}

The first clear demonstration of an anterograde pathway from the PT to the PD came from studies of the effects of surgical disconnection of the pituitary from the hypothalamus (hypothalamic-pituitary disconnection; HPD) in sheep. This surgery damages the ME and arcuate nucleus, effectively removing the hypothalamic drive from gonadotrophin-releasing hormone $(\mathrm{GnRH})$ neurones to gonadotrophs, which leads to a hypogonadal state. ${ }^{47}$ However, seasonal rhythms in PRL secretion that control seasonal changes in pelage in birds and mammals ${ }^{48}$ remain photoperiodic in HPD rams. ${ }^{49}$ Moreover, HPD rams keep on exhibiting circannual rhythmicity in PRL secretion. ${ }^{26}$ Co-culture of ovine PT and PD cells revealed that PT cells stimulate PRL production by lactotrophs, suggesting that PT cells produce an unknown PRL releasing factor, which was then dubbed "tuberalin". ${ }^{50}$ Similar findings were reported in Syrian hamsters. ${ }^{51} \mathrm{~A}$ hypothetical model was proposed for tuberalin regulation of PRL production via melatonin, ${ }^{52}$ based on the observed inhibitory effects of melatonin on cAMP production in pituitary cell cultures initially stimulated by forskolin. ${ }^{53}$ This model requires an unknown endogenous stimulator of CAMP within the PT, which was termed "Stim X". ${ }^{52}$ The crux of the model is the balance between "Stim X" activation and melatonin-mediated inhibition of cAMP production, which would direct seasonal expression of tuberalin (predicted to be a CRE-dependent gene) and, in turn, PRL secretion.

The cell signalling mechanisms used to interpret the seasonal melatonin signal remain unclear. Indeed, melatonin onset not only acts as an inhibitor, but also stimulates the expression of a range of genes in the PT, which further complicates the model. ${ }^{54-58}$ In the $\mathrm{PD}$, dopamine acting through $\mathrm{D} 2$ receptors on lactotrophs inhibits CAMP and PRL. ${ }^{59-61}$ The D1 receptor on the other hand stimulates cAMP production via activation of adenylate cyclase in neurones. ${ }^{62}$ In the ovine PT, only the D1 receptor is expressed. ${ }^{41,63}$ Furthermore in an acute melatonin infusion paradigm, D1 receptor is one of the most highly differentially expressed genes in the PT. ${ }^{58}$ This suggests that D1 receptors in the PT and dopamine signalling via these receptors could increase cAMP and fulfil the predicted role of Stim X.

The contribution of dopamine to seasonal PRL secretion has been dismissed in a study focusing on the D2 receptor (and therefore PD lactotrophs). ${ }^{61}$ One study showed that D1 receptor analogues stimulated PRL secretion in sheep; however, the site of action was not defined. ${ }^{64}$ Evidence for an action of D1 receptor signalling in the PT comes from studies on Npas4, a gene that is acutely responsive to melatoni ${ }^{58}$ and de-repressed in response to D1 receptor signalling. ${ }^{65}$ NPAS4 is also known for its roles in regulating cellular plasticity. ${ }^{65}$ If dopamine signalling via D1 receptor and downstream CAMP signalling are important for seasonal PRL regulation, then searching for differentially expressed genes in these pathways might constitute a first step towards determing the mechanisms used to interpret the seasonal message carried by melatonin.

More than 30 different factors are known to trigger PRL secretion. ${ }^{66}$ In this context, the identification of a PT-specific factor (ie tuberalin) is even more challenging. Over the years, several candidates have been put forth, such as tachykinin 1 and neurokinin A (NKA) peptides in sheep ${ }^{67}$ or endocannabinoids in hamsters. ${ }^{68,69}$ Specifically, the endocannabinoid 2-arachidonoylglycerol (2-AG) produced by the PT increases PRL release in the presence of adenosine or forskolin in Syrian hamsters. ${ }^{69,70}$ Strikingly, receptors for both NKA and 2-AG are not expressed by lactotrophs but, instead, by folliculostellate cells of the pituitary gland. ${ }^{67-69}$ Therefore, folliculostellate cells might be an important relay for transducing seasonal information towards lactotrophs. ${ }^{17}$ However, as it stands, it is plausible that the identity of the "true tuberalin(s)" remain(s) to be disclosed. In this context, it is noteworthy that RNA-sequencing (RNAseq) in sheep identified multiple PT-secreted factors of yet-to-be-determined functions ${ }^{41,63}$ (see below).

\section{5 | SEASONAL PITUITARY REMODELLING, DIFFERENTIATION AND HISTOGENESIS}

A current model for long-term internal timekeeping mechanisms proposes individual cell binary switching in the PT, leading to a 
progressive tissue level response and subsequent physiology cycles. ${ }^{71}$ This model is based on a recent study in sheep showing that individual PT thyrotrophs exist either in a winter or a summer state (Figure 2), defined by the expression of chromogranin A (CHGA) or $\mathrm{TSH}$, respectively. ${ }^{41}$ Whether this model is present in other circannual species is unknown, although it illustrates that mechanisms pertinent to cell and tissue plasticity might be involved in timekeeping devices. Indeed, a large number of genes involved in cellular plasticity and differentiation are differentially expressed according to the season in PT and $\mathrm{MBH} .{ }^{41,63}$ It has been proposed that seasonal timing relies on histogenic processes. ${ }^{72}$ However, plasticity at the level of the PT, rather than histogenesis, may be key. ${ }^{71}$ Although these are not mutually exclusive explanations ${ }^{71}$ in that histogenesis appears to be a strong seasonal feature of the $\mathrm{MBH}$, the evidence for histogenesis in the PT is inconsistent ${ }^{41,73,74}$ (see below).

Cellular differentiation and development are regulated by epigenetic processes. Interestingly, a number of enzymes involved in chromatin remodelling are expressed in the ovine PT, where their expression is increased under LP. ${ }^{41,63}$ The histone methyltransferase $\mathrm{EZH} 2$, a member of the PRC2 complex that lays down the repressive $\mathrm{H} 3 \mathrm{~K} 27$ me 3 mark, is one of these. EZH2 is required for proper differentiation of lung secretory cells during development ${ }^{75}$ and promotes neuronal differentiation in adults, ${ }^{76}$ which makes EZH2 an attractive candidate for the regulation of seasonal cycles of differentiation. SUV39H2, another PT-expressed histone methyltransferase, also displays a large increase in expression under LP compared to

(A)

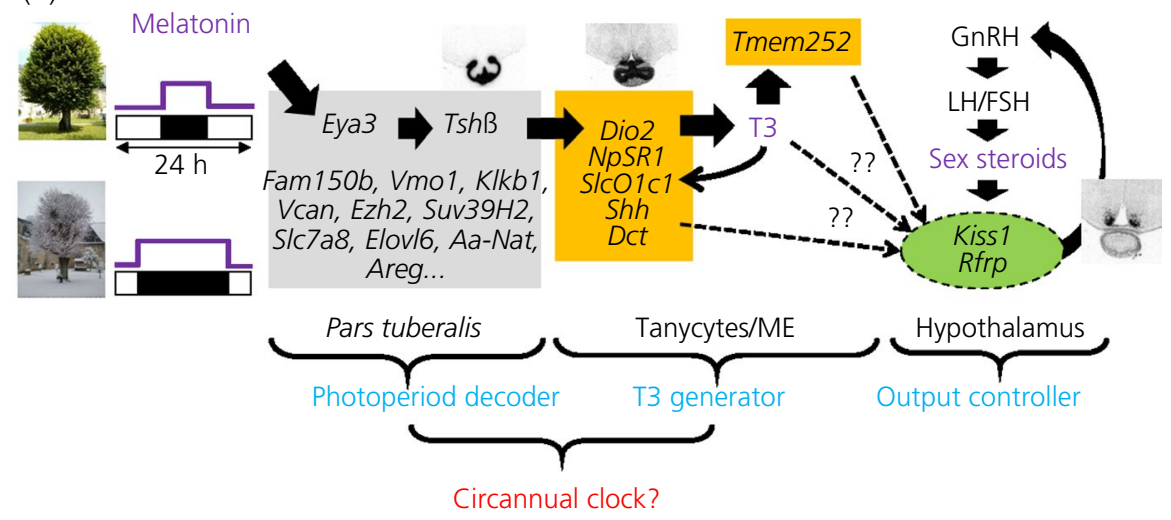

(B)

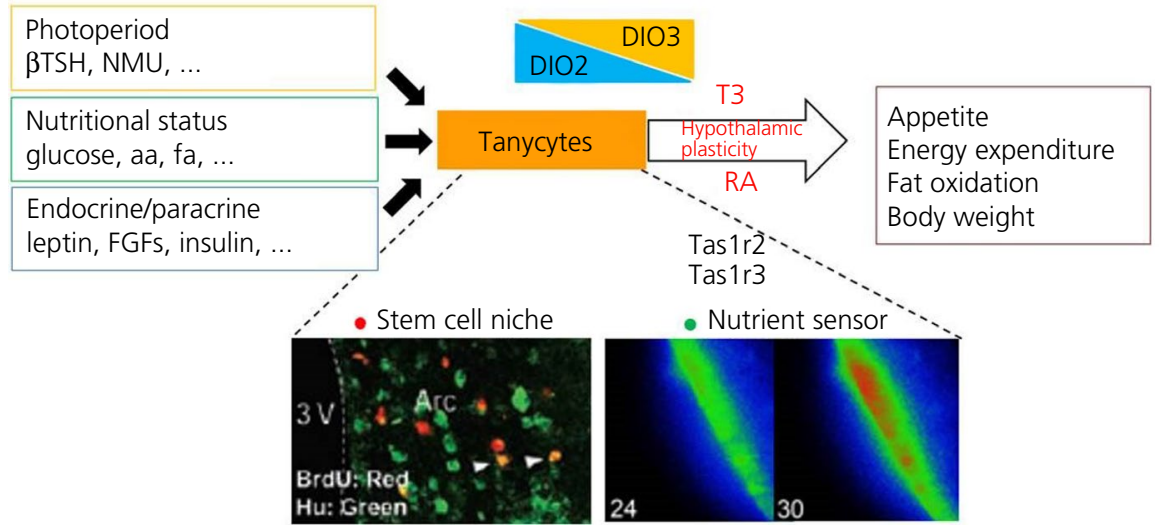

FIGURE 3 Key roles for pars tuberalis (PT) and tanycytes in the seasonal control of breeding and food intake. A, Model for the seasonal control of the gonadal axis by the PT-DIO axis in sheep. Under a long photoperiod (LP), low melatonin action in the PT translates into up-regulation of the Eya3/Tshß/Dio2 axis. We recently identified novel PT-expressed genes that display photoperiodic variations. Their respective roles and their potential control by EYA3 are unknown. Within tanycytes, thyroid-stimulating hormone (TSH) triggers Dio2 expression and triiodothyronine (T3) production. We identified several novel genes that display large photoperiodic variation and regulation by autocrine T3 feedback. These genes might govern seasonal gonadotrophin-releasing hormone (GnRH) output, perhaps by acting at the level of the median eminence. Finally, the expression of both Kiss1 and Rfrp, modulators of GnRH, are also subject to photoperiodic control; whether this depends upon input from tanycytes or factors coming from the PT remains unknown (question marks). The circannual clock might be located in the PT; it might also comprise tanycytes. Adapted from Lomet et al ${ }^{63}$ and Dardente and Lomet. ${ }^{109}$ FSH, follicle-stimulating hormone; LH, luteinising hormone; ME, median eminence. B, Tanycytes are a hub for a host of environmental signals towards the regulation of food intake and metabolism. Not only photoperiod, but also nutritional status and various endocrine and paracrine signals impinge on tanycytes. These signals interact to regulate the DIO2/DIO3 balance, hence T3 signalling within the hypothalamus. At least in hamsters, retinoic acid (RA) signalling might modulate T3 signalling. This complex network finely tunes various aspects of metabolism. Lower: tanycytes comprise a population of stem cells and directly sense nutrients. 3V, third ventricle; ARC, arcuate nucleus; BrdU, bromodeoxyuridine 
SP. ${ }^{41,63}$ Overall, at least 20 different chromatin and histone modifiers show differential seasonal expression in the ovine $\mathrm{PT} .{ }^{41}$ Seasonal changes in expression of a reduced number of chromatin modifiers have also been observed in the hypothalamus (see below). Although a role for seasonal differentiation cycles and epigenetics are distinct possibilities, ${ }^{71}$ defining the seasonal chromatin landscape of the PT will be required before a functional role for epigenetic processes in seasonal timing can be assumed.

The gross anatomy of the sheep PT shows seasonal changes at the cellular level, including junctional contacts between folliculostellate cells and PT-specific thyrotrophs ${ }^{41}$ (Figure 2). PT thyrotrophs increase in size, increase rough endoplasmic reticulum, gain a secretory phenotype and reorganise into networks on LP, presumably to coordinate TSH secretion. ${ }^{41}$ Clearly, the PT region undergoes seasonal remodelling, although the distinction between morphological remodelling as a consequence of the new physiological function to be fulfilled, or remodelling that drives a timer process, remains to be determined.

\section{6 | CONSERVED SEASONAL RETROGRADE PATHWAYS: FROM THE PT TO THE HYPOTHALAMUS}

The current model of photoperiodic entrainment focuses on a conserved retrograde pathway involving secretion of TSH from the PT which, acting on the deiodinase-expressing tanycytes cell layer surrounding the ventral third ventricle (3V) of the hypothalamus, governs local TH metabolism (Figures 1 and 3). Seasonal regulation of $\mathrm{TH}$ is crucial for the expression of seasonal rhythms in multiple vertebrate species. ${ }^{3-5,17}$ Most of our current understanding on the PT-hypothalamus retrograde pathway revolves around the observation that the changing nocturnal duration of melatonin governs local expression of Tsh $\beta$ from the PT. ${ }^{77}$ The current model of photoperiodic entrainment emphasises that changes in melatonin signal are transduced by a circadian based "coincidence timer" in the PT. ${ }^{77,78}$ This timer uses the duration of the melatonin signal to dictate the amplitude of expression of the transcriptional co-activator EYA3 that impinges on Tsh $\beta$ expression. ${ }^{77}$ In LP, increased expression of Eya3 leads to the up-regulation of Tsh $\beta$, whereas this system is tuned down in $\mathrm{SP}^{77,78}$ (Figure 3A).

Although this model is based on melatonin-induced changes in Eya3 expression driving the changes in Tsh $\beta$ expression, endogenous switches in the expression of these genes have also been observed in the PT of sheep maintained in a constant photoperiodic environment, with an unchanging melatonin pattern. ${ }^{41,79}$ Photoperiodic synchronisation of Tsh $\beta$ expression can also occur in the absence of melatonin, as recently observed in PX European hamsters. ${ }^{80} \mathrm{~A}$ recent study in reindeer showed that exposure to constant light or constant darkness do not prevent seasonal life history to proceed as anticipated, ${ }^{81}$ which suggests that circadian rhythmicity may not be a prerequisite for seasonal rhythmicity in this species. The need for circadian clock(s) to drive seasonal rhythms has long been established, ${ }^{12,82,83}$ although current data favour a dual model in which the "generation of long-term cycles depends on the interaction between a circadian-based, melatonin-dependent timer that drives the initial photoperiodic response and a non-circadian-based timer that drives circannual rhythmicity in long-lived species". ${ }^{22,84}$ Current data suggest that the EYA3/TSH/DIO "seasonal backbone" is a crucial component of both the melatonin-dependent photoperiodic input pathway and the melatonin-independent circannual timer. $^{20,41,79}$ Therefore, we anticipate that insights into the regulation of these genes, as well as how they link photoperiod decoding to circannual timing, will shed light on the nature and organisation of seasonal timers.

\section{7 | SEASONALITY IN TANYCYTES}

Seminal work in quail ${ }^{85,86}$ and sheep ${ }^{87}$ demonstrated a key role for tanycytes in the control of seasonal breeding. Through their expression of TSH receptor (TSHR), tanycytes sense PT-specific $\mathrm{TSH}^{88}$ which translates into an opposite seasonal regulation of Dio2 and Dio3. DIO2 converts circulating thyroxine (T4) into the more biologically active T3, whereas DIO3 degrades T4 and T3 to inactive reverse T3. ${ }^{89}$ Importantly, in all seasonal species studied, LP has the same effect towards an increase in the Dio2/Dio3 ratio, which translates into an increased local T3 production under LP in quail ${ }^{85}$ and Syrian hamster ${ }^{90}$ but not in F344 rats. ${ }^{91}$ Furthermore, we acknowledge that direct evidence for an LP-induced increase in T3 levels in the $\mathrm{MBH}$ of short-day breeders such as sheep or goats is still missing. Bearing these caveats in mind, we assume that local T3 levels are increased under LP whatever the seasonal physiology and reproductive season of the species. This assumption implies that mechanisms downstream of LP-induced T3 production likely diverge to produce the full repertoire of reproductive outputs: from inhibition in sheep, to activation in hamsters, and no overt effect in most strains of mice and rats.

Square wave changes in photoperiod and melatonin are sufficient to regulate Dio2 and Dio3 expression in tanycytes. ${ }^{79,87,92-94}$ TSH directly up-regulates the expression of Dio2 ${ }^{87,92}$ and, although there is evidence for Dio3 down-regulation as well, the underlying mechanism remains unknown. ${ }^{92,95}$ Strong evidence in sheep and hamsters shows that rapid activation/deactivation of this axis is sufficient to prime long-term seasonal changes in physiology. ${ }^{27,96,97}$ However, the long-term dynamics of these responses differ between species. Taking this into consideration, levels of expression along the TSH/DIO/T3 axis (especially at the level of Dio2/Dio3 expression in tanycytes) might not necessarily be congruent with the physiological output. This observation implies that "unexpected" level of expression of any of these markers is not sufficient to dismiss or undermine the role of this axis. However, the differing temporal relationship between Dio2 and Dio3 in Siberian hamsters under square wave or natural photoperiods may indicate that additional PT-derived signals regulate Dio3 expression and perhaps also modify Dio2 expression. ${ }^{96}$ 
Another PT-derived candidate is neuromedin $\mathrm{U}(\mathrm{NMU})$, which is governed by photoperiod in juvenile Fischer 344 rats $^{95}$ (Figure 3B). The NMU-R2 receptor is highly expressed in the ependymal cell layer containing tanycytes in rodents ${ }^{98}$ and i.c.v. infusion of NMU in F344 rats upregulates Dio2 but does not affect Dio3. ${ }^{95}$ Although further studies on PT-tanycyte signalling are needed, it is established that changes in tanycyte gene expression ensure a local hypothalamic metabolism of $\mathrm{TH}$, disconnected from the traditional hypothalamo-pituitary thyroid axis, and bring together the long-recognised roles of melatonin and TH in seasonal breeding. 3,63,88,94,99

\section{8 | TANYCYTES: DIFFERENT SUBTYPES AND DIFFERENT ROLES?}

Tanycytes are a specialised type of ependymal cells, which line the walls of the $3 \mathrm{~V}$ and send long processes toward hypothalamic nuclei and the ME/PT region (Figure 3). The strategic location of tanycytes at the interface between the cerebrospinal fluid and the pituitary blood flow at the ME suggests key functions in the blood-brain barrier and in the selective transport of molecules between compartments ${ }^{100,101}$ and in nutrient sensing. ${ }^{102,103}$ Even though these cells were described over a century ago, and their morphology has been studied extensively, comparatively little is known regarding their functions. ${ }^{101}$ Below, we briefly address recent findings which shed new light on the role of tanycytes in the control of seasonal functions.

Tanycytes are usually classified according to their location along the dorsoventral axis of the $3 \mathrm{~V}: \alpha 1$ and $\alpha 2$ tanycytes occupy the most dorsal positions, whereas $\beta 1$ and $\beta 2$ tanycytes line the infralateral and basal parts of the $3 V^{100,101,104,105}$ The $\alpha$ tanycytes send their processes towards the dorsomedial/ventromedial nuclei of the hypothalamus, $\beta 1$ towards the ventro-medial/arcuate nuclei of the hypothalamus and $\beta 2$ tanycytes towards the ME/PT region. Although this classification has been useful, recent data show that it largely undermines the diversity of tanycytes. Single cell RNAseq and hierarchical clustering applied to the $\mathrm{MBH}$ reveals many more molecular phenotypes, both for neurones and glial cells, than usually recognised. ${ }^{106-108}$ This has been perfectly summarised by Chen et al ${ }^{106}$ who analysed tanycytes in some detail: "Notably, although specific marker genes (or combinations of marker genes) can be used to roughly separate tanycyte subtypes, many genes exhibited a gradient, rather than a clear-cut distribution across tanycyte subpopulations consistent with the notion that tanycytes may be composed of continuous cell trajectory with transition zones between different subtypes." Although all three single-cell RNAseq studies were performed in the mouse, there is no a priori reason to assume such complexity would not apply to other species. It is worth keeping in mind the wide variety of tanycytes and their current simplified classification to interpret future studies, especially when using classical approaches (ie, quantitative reverse trasnscriptase-polymerase chain reaction or in situ hybridisation). Further discussion on this topic is provided by Prévot et al. ${ }^{101}$

\section{9 | NOVEL SEASONAL MARKERS FOR TANYCYTES IN SHEEP: A ROLE FOR AUTOCRINE/PARACRINE THYROID HORMONE FEEDBACK?}

Amongst the strongest seasonal markers identified by our recent RNAseq analysis in sheep, many were found to be expressed exclusively in the PT, although a few were also found to be expressed specifically in tanycytes as revealed by in situ hybridisation ${ }^{63,109}$ (Figure 3). Apart from Dio2 and the TH transporters MCT8 (SIc16a2) and Oatp1c1 (SIcO1c1), we further identified Shh, Tmem252, NpSR1 and Dct as novel tanycyte-specific markers regulated by photoperiod and $\mathrm{TH}$, as suggested by the outcome of experiments in which a chronic lack of TH (5-6 months) was achieved through surgical thyroidectomy (THX). These four genes appear to be exclusively expressed by tanycytes located in the infra-lateral walls and bottom of the $3 \mathrm{~V}$, which suggests they are $\beta$ tanycytes. These genes show specific response to photoperiod and TH: Shh, Dct and Tmem 252 show higher expression under LP, whereas NpSR1 is a SP marker. Interestingly, expression of not only Shh and Dct, but also Dio2 and SIcO1c1 is induced by acute exposure to LP and is increased by THX, irrespective of photoperiod. By contrast, Tmem 252 is also induced by acute exposure to LP, although this induction is severely blunted in THX animals, ${ }^{63,109}$ which suggests Tmem 252 plays a specific role as relay of the LP message carried by TH. Finally, expression of NpSR1 is not induced by acute exposure to LP and THX leads to constant intermediate levels. We also note that the impact of TH on expression of some of these genes might reflect longer-term effects because it is not seen in animals studied 1 month after THX. ${ }^{63} \mathrm{~A}$ strategy of TH replacement, perhaps through the use of hypothalamic implants, in THX animals should be used to clarify the role of TH.

Most importantly, there is strong evidence that $\mathrm{SHH}$, DCT and NPSR1 are involved in processes linked to plasticity and cell proliferation. ${ }^{110-114}$ A potential role for TMEM252 remains to be investigated because there are almost no data available in the literature for this gene. This appears to place the emphasis back (again) on the potential role of cell proliferation and histogenesis in long-term timing programmes. ${ }^{72}$

\section{0 | SEASONAL STRUCTURAL REMODELLING IN TANYCYTES}

Tanycytes show a remarkable seasonal remodelling of their cytoplasmic processes and cytoskeletal composition. Studies using Japanese quail (long-day breeders) revealed seasonal remodelling of tanycyte endfeet at the level of the PT, ${ }^{115}$ such that GnRH terminal fields specifically contact the pericapillary space only during the breeding season (LP). This remodelling is also observed in SPkept sheep (short-day breeders) or sheep endogenously reactivating their reproductive axis in a constant photoperiod ${ }^{41}$ (Figure 2). Tanycyte end-feet retraction is also associated to an altered sex steroid milieu during the transition to oestrous in rats, ${ }^{116}$ situating 
this phenomenon as part of the reproductive output and not of the photoperiodic response itself.

In tanycytes, the cytoskeletal proteins vimentin and neural cell adhesion molecule show reduced expression in SP compared to LP in hamsters, ${ }^{117,118}$ which is associated with changes in melatonin but not sex steroids. Morphological studies in sheep have demonstrated the increased expression of these structural markers during the winter season instead, associated to an increase in the thickness of the tanycytic nuclear layer, junctions between cells and tanycytes protrusions into the $3 \mathrm{~V}$ at the arcuate nucleus level ( $B 1$ tanycytes), ${ }^{119}$ reinforcing the view that such changes occur as a consequence of the seasonal response associated to the season of breeding (ie, sex steroid-dependent process).

Akin to that observed for the PT (see above), several genes related to the modification of chromatin structure (eg, DNA methyltransferases and histone deacetylases) undergo seasonal and photoperiodic variation in tanycytes of Siberian hamster and F344 rats, which suggests that epigenetic changes occur in a coordinated manner in PT and tanycytes. ${ }^{120-122}$

\section{1 | TANYCYTES AS STEM CELLS: DOES HYPOTHALAMIC CELL PROLIFERATION PLAY A ROLE IN CIRCANNUAL RHYTHMS?}

Subsequent to the initial demonstration in mice and rats that tanycytes comprise a population of stem cells that can be induced to proliferate (as assessed by bromodeoxyuridine incorporation) by growth factors such as basic fibroblast growth factor (bFGF) and ciliary neurotrophic factor (CNTF), ${ }^{123,124}$ the stem cell niche of the $\mathrm{MBH}$ has been described in other mammals, including sheep and humans ${ }^{73,74,119,125}$ (Figure 3B). This topic has been extensively reviewed recently. ${ }^{101,105}$ Here, we briefly consider the potential relevance of local cell proliferation to circannual rhythmicity and photoperiodic responses. Fate-mapping studies in the mouse, aimed at identifying which population of tanycytes truly comprises stem cells, have pointed either to $\alpha$ tanycytes $^{126}$ or $\beta$ tanycytes. ${ }^{127}$ Potential stem cells have also been identified within the hypothalamic parenchyma, rather than among tanycytes. ${ }^{128}$ At least in sheep, bromodeoxyuridine-labelled cells are also found within the PT/ME, ${ }^{73,74}$ although a high proportion of these might be microglia. ${ }^{74}$ Therefore, it is safe to conclude that the location of stem-cells within the $\mathrm{MBH}$ is still a matter of debate and that species-specificity in proliferation processes is plausible.

Unsurprisingly, most of the studies investigating hypothalamic cell proliferation have been performed in laboratory strains of mice and rats, which are not overtly photoperiodic. However, there is good evidence that hypothalamic cell proliferation is increased under SP in sheep, ${ }^{73,74,129}$ and there is limited evidence for a heightened number of dividing cells under SP than LP in the golden hamster ${ }^{130}$ and F344 rats. ${ }^{131}$ What might trigger seasonal cell proliferation? As noted above, cell proliferation can be prompted by a variety of growth factors including bFGF, CNTF or insulin-like growth factor (IGF)1. ${ }^{123,124,132} \mathrm{We}$ note that expression of Areg, a ligand of the epidermal growth factor receptor (EGFR), was transiently up-regulated in the $\mathrm{MBH}$ of ewes sampled in August. ${ }^{63}$ Several members of the IGF1 signalling pathway also appeared to be regulated by season. ${ }^{63}$ Whether EGFR or IGF1 signalling also play roles in seasonal timing and cell proliferation remains unknown. Placing these considerations in the perspective of seasonal timing, one may envision a model in which various growth factors sequentially activate (or repress) proliferation of different subsets of stem cells, at different location in the ventricular walls or in the median eminence or within the hypothalamic parenchyma. To the best of our knowledge, the potential direct role of other secreted factors such as TSH or $\mathrm{NMU}^{95,133}$ on cell proliferation in the $\mathrm{MBH}$ has not been investigated (Figure 3B).

Recent evidence obtained in sheep, using infusion of the anti-mitotic compound Ara-C at the bottom of the $3 \mathrm{~V}$, hints at a functional role for tanycytic cell proliferation in the timing of the breeding season. ${ }^{129}$ How cell proliferation may impact seasonal timing remains unknown. ${ }^{72}$ Do newborn cells integrate specific circuits? Alternatively, because tanycytes play an important barrier role, is it possible that proliferation leads to transient disorganisation/reorganisation of the barrier properties? In other words, is proliferation per se the important factor?

These questions arise from the limited number of newly generated cells observed under SP and the differences in seasonal programmes between species. As noted above, cell proliferation is increased under SP in both sheep and golden hamster and thus appears to be a conserved mechanism, as is the photoperiodic regulation of the TSH-DIO axis. ${ }^{3,86,134}$ Although photoperiodic regulation of cell proliferation has not been evaluated in nonphotoperiodic rodents, we may anticipate an increase under SP if proliferation is coupled to the TSH-DIO axis. Although we agree that species-specific differences in seasonal programmes likely arise downstream of this axis, it is not immediately obvious that cell proliferation (alone) could account for the wide spectrum of seasonal phenotypes. In other words, these new cells would govern (i) short-day breeding without notable changes in body weight for sheep; (ii) long-day breeding with a fast $30 \%$ body weight loss during autumn and preparation for winter torpor cycles in the Siberian hamster; and (iii) long-day breeding with weight gain and preparation for hibernation in the golden hamster. To summarise, a functional role for cell proliferation/histogenesis in seasonal timing is plausible, although current data are not sufficient to draw firm conclusions regarding mechanisms.

\section{2 | SENSITISATION OF THE TSHR SIGNALLING PATHWAY IN TANYCYTES}

Seasonal changes in tanycyte sensitivity to TSH stimulation may be integral to internal timing mechanisms. Although there is evidence that the endogenous down-regulation of the TSH-DIO axis may be central to the transition from summer to winter physiology in sheep, ${ }^{41,63,79}$ data are inconsistent, with a converse increase in $T s h \beta$ expression during the intrinsic transition to summer physiology 
(A) Photoperiod (h)

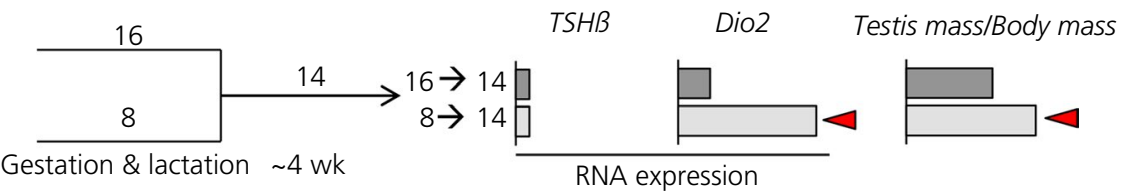

(B)

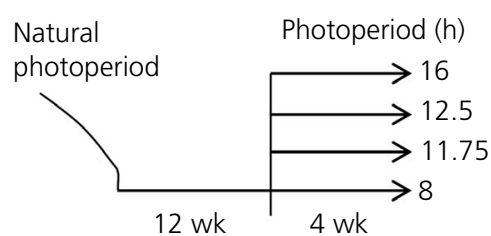

12 wk

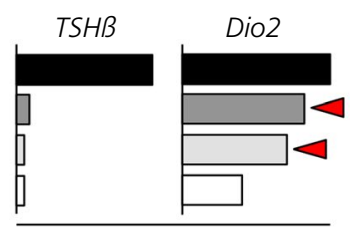

RNA expression

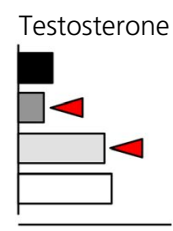

Final level

(c)

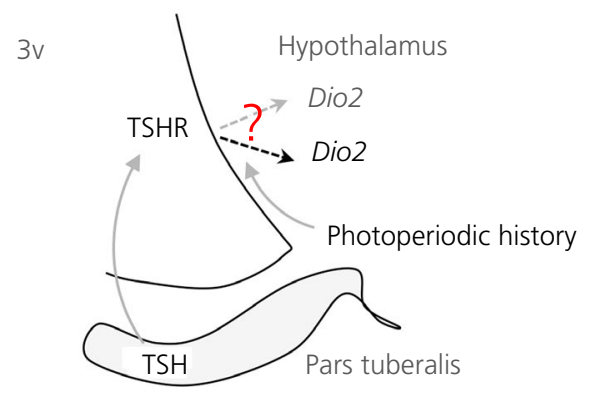

FIG URE 4 Sensitisation of thyroid-stimulating hormone (TSH) receptor signalling in tanycytes is affected by photoperiodic history. A, Siberian hamsters with a long photoperiod (LP) (16 hours light/day) or short photoperiod (SP) (8:16 hours light/day) history show a similar level of pars tuberalis (PT) TSHß expression when raised in intermediate photoperiod (14:10 h light/dark cycle). However, dio2 gene expression and in turn testis size are highly increased (red arrowheads) in animals with short photoperiodic history (8 $\rightarrow 14)$ compared to animals with long photoperiodic history $(16 \rightarrow 14)$. Adapted from Sáenz de Miera et al. ${ }^{40}$ B, Sheep with a history of SP (8:16 hours light/dark cycle) exposed to stepwise increases in photoperiod show increases in dio2 gene expression with minimal or no change in TSH $\beta$ expression. This change is reflected in testosterone levels that switch over photoperiods in the range from 11.75 hours to 12.5 hours (red arrowheads). Adapted from Hazlerigg et al. ${ }^{136} \mathrm{C}$, Photoperiodic-history affects tanycyte sensitivity to TSH signalling at a level that remains to be determined (question mark), leading to differential dio2 gene expression in response to a given PT TSH signal. 3V, third ventricle; TSHR, TSH receptor

observed in different species. ${ }^{20,42,79,97,135}$ This does not necessarily mean that this switch is TSH-independent. Instead, our recent work in hamsters and sheep reveals changes in sensitivity to TSH in response to prior photoperiod and thus exposure to Tsh $\beta$ history (Figure 4).

When Siberian hamsters with either LP- (ie, high TSH) or SP- (ie, low TSH) history are raised in intermediate photoperiod (14:10 hours light/dark cycle), they show similar intermediate levels of PT-Tsh $\beta$ expression, as assessed by in situ hybridisation. By contrast, expression of Dio2 is highly increased only in those animals with a SP-history (ie, low TSH-history) compared to animals with a LP-history (ie, high TSH-history) ${ }^{40}$ (Figure 4A). Furthermore, when juveniles with different photoperiodic history received small i.c.v. doses of TSH, juveniles with a SP-history had higher Dio2 expression compared to those with a LP-history, demonstrating a difference in TSH signalling sensitivity dependent on the previous photoperiodic history of the animals. ${ }^{40,42}$

Similarly, using stepwise increases in photoperiod after exposure to SP in sheep, we recently showed that a small increase in photoperiod, thus a small increase in PT-Tsh $\beta$ expression, leads to sub-maximal Dio2 expression (ie, identical to LP expression) (Figure 4B). We consider that this reveals sensitisation of the TSHR signalling pathway after prolonged deprivation of TSH during winter months. Moreover, this shows that Tsh $\beta$ expression can be increased by photoperiods considered as short (approximately 11 hours ${ }^{136}$; H. Dardente and D. Lomet, unpublished data). Collectively, this indicates that sensitisation/desensitisation of signalling pathways in tanycytes (and PT perhaps) plays a significant role in seasonal cycles. We propose that sensitisation of the TSH signalling pathway (ie, at the TSHR or downstream) might be a key component of the photoperiodic history in mammals (Figure $4 \mathrm{C}$ ).

\section{3 | INTEGRATION OF SEASONALITY INTO METABOLIC PHYSIOLOGY}

Perhaps, the greatest remaining challenge for the field is to establish how changes in tanycyte-directed plasticity and signalling in the 
$\mathrm{MBH}$ ultimately impact on the known neuroendocrine pathways that underpin fertility and energy balance (Figure 3B). The experimental observations indicating that direct placement of $\mathrm{TH}$-releasing microimplants in the $\mathrm{MBH}$ can induce reproductive and metabolic physiology mimicking the LP state in hamsters ${ }^{94,137}$ and sheep ${ }^{138}$ are consistent with the studies reviewed above indicating enhanced Dio2 expression and thus local TH availability in LP. However, this same signal elicits activation of the GnRH secretory system in hamsters but inhibition in sheep. Moreover, in the melatonin-producing strain of CBA/N mice, changes in photoperiod elicited TSH-dependent regulation of Dio2 in tanycytes, although this did not translate to any effect on the reproductive axis, at least within the short time frame of the study. ${ }^{92}$ One potential explanation for these paradoxes is that we do not yet know the direct targets of $\mathrm{TH}$ (also see above). There are likely to be multiple targets: a study in a hypothyroid rat model identified $>100$ genes that were up- or down-regulated in the hypothalamus following TH replacement. ${ }^{139}$ Perhaps differences in these targets between species may explain the evolution of different seasonal timing.

A second explanation is that, although under experimental conditions central manipulation of TH is sufficient to modify seasonal cycles, it appears likely that multiple tanycyte-derived signals change seasonally, which then also modify neuroendocrine responses. For example, studies in both Siberian hamsters and F344 rats have identified up-regulation of genes encoding retinoic acid (RA) transporters, binding proteins and receptors in tanycytes under LP ${ }^{140,141}$ (Figure 3B). Given that both TH and RA signalling act in concert to regulate initial brain development, it is likely that this is also the case for directing seasonal plasticity and change in function in the adult brain. ${ }^{131}$ In these species, expression of several elements of the Wnt signalling pathway in the $\mathrm{MBH}$ is not only up-regulated under LP, but also by leptin and NMU administration, suggesting that this developmental pathway might be involved in seasonal body weight regulation. ${ }^{95,142}$

An initial expectation that followed the identification of the PT as central to photoperiodic signalling in mammals was that the downstream effects of seasonal changes in appetite and energy expenditure would be the well-researched peptidergic pathways (NPY, agouti-related peptide, pro-opiomelanocortin [POMC]/ $\alpha-$ melanocyte-stimulating hormone, cocaine- and amphetamine-regulated transcript) identified in the $\mathrm{MBH}$ that are critical in short-term homeostatic control. ${ }^{143}$ Some studies in jerboas ${ }^{144,145}$ or in sheep support this conjecture; for example, increased expression of the "orexigenic gene" Npy has been found in rams and ewes in the nonbreeding season when appetite increases, ${ }^{146,147}$ although recent studies in red deer present a much more complex picture with opposite seasonal regulation of NPY in male and female animals. ${ }^{148}$ Moreover, extensive studies in Siberian hamsters from three different research groups found a consistent decrease in POMC gene expression despite showing a consistent weight loss in SP, although they failed to find photoperiodic changes in these peptidergic systems that correlate with altered appetite. ${ }^{149-151}$ Although POMC appears to be involved in the long-term timing of energy balance, we clearly need to look beyond these peptidergic systems to understand long-term rheostatic control of appetite.

One particularly interesting candidate is the VGF system, which is not only one of the most widely and highly expressed genes in the hypothalamus, ${ }^{152}$ but also shows clear seasonal regulation in the arcuate nucleus of Siberian hamsters. ${ }^{153}$ Importantly, it is a TH-regulated gene and thus a potential direct target of altered tanycyte signalling, ${ }^{154}$ and up-regulation of gene expression in the hamster hypothalamus (using a recombinant adeno-associated viral vector) increased energy expenditure and reduced body weight gain. ${ }^{155}$ Unfortunately, processing of the proVGF precursor is complex and tissue-specific, comparable to the biology of POMC processing; thus, overexpression of Vgf resulted in increased hypothalamic content of a variety of VGF-derived peptides, ${ }^{155}$ some with orexigenic activity (eg, NERP2), and others with anorectic and catabolic actions (eg, TLQP21 ${ }^{156}$ ). Clearly, more sophisticated experimental tools will be necessary to understand better the seasonal function of this peptidergic system. Another peptidergic system worthy of further study is somatostatin because hypothalamic expression of this gene decreases markedly in LP in Siberian hamsters, then increases in $\mathrm{SP}^{96}$ and expression is down-regulated by i.c.v. infusion of TSH in hamsters, suggesting again that it is a target of tanycyte-produced $\mathrm{TH} .{ }^{90}$ Somatostatin is a key inhibitor of pituitary growth hormone so likely contributes to seasonal growth cycles via this route. However, given that treatment of hamsters with the somatostatin agonist pasireotide can promote a wide range of SP responses in addition to growth/metabolic adaptations, such as gonadal involution ${ }^{157}$ and enhanced frequency of torpor bouts, ${ }^{158}$ it appears likely that somatostatin has additional central mechanisms of action.

\section{4 | CONNECTING TANYCYTES AND GNRH: THE NEUROPEPTIDES KISSPEPTIN AND RFRP3}

The conserved TSH-dependent retrograde pathway discussed above is primarily involved in the regulation of seasonal breeding. However, neurones producing GnRH are located within the hypothalamic preoptic area, rostrally to the $\mathrm{MBH}$. The question arises as to how T3 produced within the MBH impacts $\mathrm{GnRH}$ secretion, and hence LH/FSH production by the PD. It is now obvious that the KP family of neuropeptides, encoded by the Kiss1 gene, and as expressed in the arcuate nucleus of the hypothalamus, play a central role in the seasonal control of breeding, being strongly modulated by melatonin ${ }^{159}$ and by sex steroids. ${ }^{160,161}$ The neuropeptide RFRP3, encoded by the Npvf gene, which is expressed in the dorsomedial/ ventromedial nuclei of the hypothalamus, is strongly down-regulated by melatonin ${ }^{162,163}$ and may also play a role (Figures 1 and $3 A$ ). Kiss1 and Npvf display large opposite seasonal variation in expression, modulated in a sex and species-specific manner. Although Kiss1 expression is generally, but not always, ${ }^{20,164}$ higher in the breeding season, there is a conserved down-regulation of Npvf expression in short days, in all long- and short-day breeders studied. ${ }^{165}$ The role 
of these neuropeptides in seasonal breeding has been extensively reviewed over the last years. ${ }^{165-168}$

Kisspeptins has emerged as the most potent $\mathrm{GnRH}$ secretagogue and its role in the central control of all aspects of breeding, from puberty onset to regular oestrus cycles through to seasonal breeding, is unequivocal. ${ }^{169}$ By contrast, a role for RFRP3 in the control of breeding is still controversial. It was initially proposed that KP and RFPR3 play opposite roles towards the gonadal axis (the "yin/yang model"170,171). However, recent findings are inconsistent with such a simple scenario: studies in hamsters disclose a stimulatory role for RFRP3 in SP-kept male hamsters but an inhibitory role in LP ${ }^{163,172,173}$; mice KO for the Npffr1 receptor (RFRP3 receptor $^{174}$ ) had no overall fertility deficits. In sheep, RFRP3 has been reported to have no effect ${ }^{175}$ or to inhibit gonadotrophin secretion. ${ }^{176}$ In horse, RFRP3 has no effect upon GnRH-mediated LH release. ${ }^{177}$ Npvf expression might be regulated by metabolic cues ${ }^{178}$ and temperature, ${ }^{179}$ somehow obscuring the impact of photoperiod. Central TSH infusion ${ }^{90}$ or TH implants ${ }^{180}$ in long-day breeders kept under SP consistently impacted the expression of Kiss1 and Npvf, which then reverted to LP-like profiles. No data are available for any short-day breeder.

Overall, the currently available data place these two cell populations in a local hypothalamic circuit downstream of T3 production by tanycytes. Although divergence downstream of $\mathrm{T} 3$ is anticipated ${ }^{1}$, we consider it likely that differential control of these two cell populations, by mechanisms remaining to be characterised, might explain the wide array of reproductive seasonal outputs, such that the neuropeptides KP and RFRP3 might constitute the common conduit towards GnRH control (at least in mammals since birds lack a Kiss1 gene). Further studies will be required to clarify (i) whether Kiss1- and Npvf-expressing cells establish (reciprocal) synaptic communication; (ii) the impact of sex steroids, photoperiod, temperature and metabolic status upon the expression of both genes; and (iii) the anticipated role of KP at the level of the GnRH neurone endfeet in the ME. To be meaningful, these goals will have to be met in multiple species because seasonal timing of breeding is in essence a comparative question.

\section{5 | CHALLENGES AND INSIGHTS}

Our current knowledge of the central mechanisms underlying seasonality highlights a conserved neuroendocrine pathway involving PT TSH-mediated regulation of tanycyte DIO2/DIO3 balance, which in turn drives seasonal switches of T3 availability in the $\mathrm{MBH}$. As noted previously, whether the seasonal changes in deiodinase expression actually lead to corresponding modulation of T3 levels across species is contentious, especially because data are not available for short-day breeders. If we assume that the LP-triggered increase of $\mathrm{T} 3$ levels in the $\mathrm{MBH}$ is a conserved feature (ie, present in both long-day and short-day breeders), it follows that this pathway alone cannot explain the divergence in seasonal breeding and metabolic strategies. ${ }^{1}$ At this stage, there is no simple explanation to this, although we might emphasise several plausible scenarios, which are not mutually exclusive.
First, it is very likely that several species-specific paracrine/autocrine circuits operate in parallel. For example, TSH and NMU, WNT or RA might provide complementary signalling, leading to long-day activation of the HPG axis in hamsters. Notably, there are no conspicuous seasonal changes in expression of members of NMU, WNT or RA signalling pathways in sheep, ${ }^{63}$ as already noted by others. ${ }^{1}$ As mentioned earlier, species-specific combinations of specific growth factors (or others), acting at the level of tanycytes or elsewhere, might also be involved. In addition, different responsiveness to these signals might be driven by species-specific gene regulatory elements. Second, one might consider a simpler explanation, which involves hypothalamic populations expressing Kiss1 and Npvf. In mouse, approximately $90 \%$ of neurones expressing Kiss1 in the arcuate nucleus are glutamatergic, ${ }^{106,181,182}$ even though a substantial fraction may also use GABA. ${ }^{181}$ In sheep, Kiss1-expressing neurones are also mostly glutamatergic. ${ }^{183}$ In mouse, there is good evidence that Npvf neurones are glutamatergic too, ${ }^{108}$ and also that distinct subpopulations of Npvf neurones may exist. ${ }^{184}$ No data are available in sheep or hamsters regarding the neurochemical identity of Npvfexpressing neurones or the existence of neuronal subpopulations. Overall, we know very little regarding neurotransmitter content and fine organisation of neurones producing KP and RFRP3 in seasonal species. Could these neuronal (sub)populations use different neurotransmitters in different species? What about potential neuronal connections between these two neuronal populations? An effort will have to be made to provide answers to these questions in the different photoperiodic models. Third, there is strong evidence that the seasonal circuit controlling seasonal breeding in sheep involves the dopaminergic A15 nucleus, ${ }^{185,186}$ which does not exist in hamsters. Therefore, species-specific circuitry downstream of T3 might also explain the plasticity in timing of seasonal breeding.

A fourth point concerns the impact of sex steroids upon the seasonal cycle of LH/FSH and the expression of Kiss1 and Npvf. In ewes, it is obvious that $E_{2}$ is required for the seasonal switches in $\mathrm{LH} / \mathrm{FSH}^{187,188}$; it might indeed be permissive to the impact of $\mathrm{T}^{27}$ (see also above). By contrast, castration in mares, ${ }^{189}$ female quail ${ }^{190}$ or snowshoe hares of both sexes ${ }^{191}$ does not blunt seasonal fluctuations in LH/FSH. Therefore, the role played by sex steroids in the seasonal organisation is species-specific. Interestingly, sex steroids dampen Kiss1 expression in neurones of the arcuate nucleus in almost all mammals studied and this is recognised as a key feature for the control of seasonal breeding. ${ }^{166,168,192}$ The sex steroid sensitivity of Npvf-expressing neurones has comparatively received little attention and available data are discordant. ${ }^{165}$ However, gonadectomy does not appear to affect Npvf expression in Syrian, Siberian or European hamsters, ${ }^{20,162,164,173}$ although it affects the expression of Kiss1. This suggests that Npvf-expressing neurones are not bona fide targets of sex steroids and also weakens the hypothesis that the two subpopulations are synaptically connected, at least in hamsters. By contrast, our unpublished data in ewes comparing intact, OVX (ovariectomised) and $\mathrm{OVX}+\mathrm{E}_{2}$ implanted animals in May and November (seasons of anoestrus and breeding, respectively) reveals a profound and almost opposite impact of sex steroids on the expression of Kiss1 
and Npvf (H. Dardente and D. Lomet, unpublished data). This illustrates a species-specific response of Kiss1 and Npvf to sex steroids and suggests an anatomical connection (direct or indirect) between these neuronal populations in sheep. In conclusion, we surmise that species-specific temporal organisation beyond the TSH/DIO/T3 axis may be a result of the use of multiple signals, a differential use of neurotransmitters, a distinctive neuroanatomical organisation in circuits involving neurones produce KP and RFRP3, and/or a varying degree of sex steroid responsiveness of these populations or other neuronal or glial populations involved in the pathway (eg, tanycytes).

How phylogenetically conserved is the TSH/DIO/T3 axis? Thus far, compelling evidence has been gathered in multiple species of birds and mammals. There are no data about the conservation of this pathway in reptiles and amphibians, although these vertebrates have a distinct PT and show a roughly similar organisation of the $\mathrm{MBH}$ region, ${ }^{193}$ which provides neuroanatomical ground for conservation. The fish pituitary instead does not appear to include a PT-like region. ${ }^{193}$ There is some evidence for the existence of a specific TSH/ DIO/T3 axis in fish but with substantial differences from the mammalian models. In salmon, the Tshß/Dio2 response to LP is conserved, although this occurs in another directly photoreceptive structure called the saccus vasculosus. ${ }^{4,194}$ In addition, genome duplication in fish may have allowed for some level of plasticity through specialisation of paralogues along the putative TSH/DIO/T3 axis. Fleming et $\mathrm{al}^{195}$ reported the expression of two distinct Tsh $\beta$ subunits in the salmon pituitary, one of which (Tsh $\beta b$ ) exhibits a marked induction as daylength increases from late winter onwards and a specific pattern of expression in the dorsal region near the pituitary stalk, a location comparable to the PT in mammals. Differential tissue expression and a response to photoperiod has also been reported for Dio2 paralogues in salmon. ${ }^{196}$ In stickleback, Tsh $\beta$ expression in the pituitary is acutely but very transiently induced by LP exposure. ${ }^{197}$ The transient nature of the response may explain the lack of difference in Tsh $\beta$ expression observed by others in sticklebacks adapted to SP or LP. ${ }^{198}$ From a general standpoint, this finding calls for a cautious (re) interpretation of prior data, which examined and compared this axis in animals maintained under LP or SP for various durations. These gaps in our knowledge on the phylogenetic conservation of the TSH/ DIO/T3 axis have to be filled to enlighten the evolution of photoperiodic read-out mechanisms.

We thus consider comparative physiology to be key to furthering our understanding of seasonal time-keeping mechanisms. The ever-increasing availability of sequenced and annotated genomes in vertebrates along with the development and relative affordability of large-scale approaches in transcriptomics (RNAseq/single-cell RNAseq/ChIP-seq, etc.) and proteomics now makes it possible to address questions at the genome-wide level in non-model species. Such approaches should be applied to the $\mathrm{MBH}$ of multiple species under a range of photoperiodic manipulations to gain insights into the level of conservation of the TSH/ $\mathrm{DIO} / \mathrm{T} 3$ axis and other pathways. One might predict a low level of conservation, limited to a few key components, as demonstrated for circadian clocks (and clock genes) across species and tissues. (e.g. ${ }^{199}$ ). Pharmacological approaches should also be developed to investigate the seasonal change of tanycyte sensitivity to TSH signalling (and other newly identified diffusible factors, see below) because this might be central to the organisation of circannual timing.

The role of alternative signalling pathways in hamsters (eg, NMU, WNT or RA) and recently identified secreted factors in sheep (eg, Vmo1, Fam150b, Areg, Shh) ${ }^{63}$ in seasonal physiology might be explored by long-term i.c.v. infusions or hypothalamic implants, as previously performed for other peptides $90,137,159,172,173$ or the use of recombinant viral vectors, which are effective in Siberian hamsters. ${ }^{155}$ Instead, CRISPR/Cas9 technology (eg, in hamsters ${ }^{200}$ ) would be beneficial to explore the requirement of any of these genes for the seasonal response. For example, deleting Dio3 would allow a direct test of the hypothesis that a "hypothyroid MBH" state is required for the transition to winter physiology. However, the use of CRISPR/Cas9 in hamsters and sheep is arguably limited because of technical challenges, time (especially true for long-lived species), financial issues and, crucially, the fact that such an approach produces systemic mutations, which complicates data interpretation. Clearly, commercially available strains of hamsters and sheep to perform intersectional genetics, akin to the CRE-LoxP system in mouse, is way beside the point. However, the use of genetically modified mouse models could be occasionally beneficial for interrogating signalling pathways to complement studies in seasonal species (e.g. ${ }^{57,92,201}$ ). Even though our understanding of the cellular and molecular underpinnings of seasonality and circannual clocks improved significantly over the last decade, there are great challenges and many more surprises ahead of us.

\section{ORCID}

Hugues Dardente (iD https://orcid.org/0000-0001-7209-5940

Shona Wood iD https://orcid.org/0000-0002-8273-4045

Francis Ebling (iD https://orcid.org/0000-0002-7316-9582

Cristina Sáenz de Miera iD https://orcid.

org/0000-0001-8047-035X

\section{REFERENCES}

1. Helfer G, Barrett P, Morgan PJ. A unifying hypothesis for control of body weight and reproduction in seasonally breeding mammals. J Neuroendocrinol. 2019;31:e12680.

2. Hazlerigg DG, Loudon A. New insights into ancient seasonal life timers. Curr Biol. 2008;18:R795-R804.

3. Dardente H, Hazlerigg DG, Ebling FJP. Thyroid hormone and seasonal rhythmicity. Front Endocrinol. 2014;5:19.

4. Nakane Y, Yoshimura T. Universality and diversity in the signal transduction pathway that regulates seasonal reproduction in vertebrates. Front Neurosci. 2014;8:1-7.

5. Wood S, Loudon ASI. Clocks for all seasons: unwinding the roles and mechanisms of circadian and interval timers in the hypothalamus and pituitary. J Endocrinol. 2014;222:R39-R59.

6. West AC, Wood SH. Seasonal physiology: making the future a thing of the past. Curr Opin Physiol. 2018;5:1-8. 
7. Hoffman RA, Reiter RJ. Pineal gland: influence on gonads of male hamsters. Science. 1965;148:1609-1611.

8. Reiter RJ. Photoperiod: its importance as an impeller of pineal and seasonal reproductive rhythms. Int J Biometeorol. 1980;24:57-63.

9. Woodfill CJI, Wayne NL, Moenter SM, et al. Photoperiodic synchronization of a circannual reproductive rhythm in sheep: identification of season-specific time cues. Biol Reprod. 1994;50:965-976.

10. Bittman EL, Dempsey RJ, Karsch FJ. Pineal melatonin secretion drives the reproductive response to daylength in the ewe. Endocrinology. 1983;113:2276-2283.

11. Carter DS, Goldman BD. Antigonadal effects of timed melatonin infusion in pinealectomized male Djungarian hamsters (Phodopus sungorus sungorus): duration is the critical parameter. Endocrinology. 1983;113:1261-1267.

12. Goldman BD. Mammalian photoperiodic system: formal properties and neuroendocrine mechanisms of photoperiodic time measurement. J Biol Rhythms. 2001;16:283-301.

13. Elliott JA. Circadian rhythms and photoperiodic time measurement in mammals. Fed Proc. 1976;35:2339-2346.

14. Brinklow BR, Loudon AS. Evidence for a circannual rhythm of reproduction and prolactin secretion in a seasonally breeding macropodid marsupial, the Bennett's wallaby (Macropus rufogriseus rufogriseus). J Reprod Fertil. 1993;98:625-630.

15. Follett BK, Nicholls TJ. Influences of thyroidectomy and thyroxine replacement on photoperiodically controlled reproduction in quail. J Endocrinol. 1985;107:211-221.

16. Butler MP, Turner KW, Park JH, et al. Seasonal regulation of reproduction: altered role of melatonin under naturalistic conditions in hamsters. Proc Biol Sci. 2010;277:2867-2874.

17. Wood S, Loudon A. The pars tuberalis: the site of the circannual clock in mammals? Gen Comp Endocrinol. 2018;258:222-235.

18. Lincoln GA. A brief history of circannual time. J Neuroendocrinol. 2019;31:e12694.

19. Kondo N, Sekijima T, Kondo J, et al. Circannual control of hibernation by HP complex in the brain. Cell. 2006;125:161-172.

20. Sáenz de Miera C, Monecke S, Bartzen-Sprauer J, et al. A circannual clock drives expression of genes central for seasonal reproduction. Curr Biol. 2014;24:1500-1506.

21. Malpaux B, Robinson JE, Brown MB, et al. Reproductive refractoriness of the ewe to inductive photoperiod is not caused by inappropriate secretion of melatonin. Biol Reprod. 1987;36:1333-1341.

22. Lincoln GA, Johnston JD, Andersson $\mathrm{H}$, et al. Photorefractoriness in mammals: dissociating a seasonal timer from the Circadianbased photoperiod response. Endocrinology. 2005;146:3782-3790.

23. Zucker I. Pineal gland influences period of circannual rhythms of ground squirrels. Am J Physiol Regul Integr Comp Physiol. 1985;249:R111-R115.

24. Masson-Pévet M, Naimi F, Canguilhem B, et al. Are the annual reproductive and body-weight rhythms in the male European hamster (Cricetus cricetus) dependent upon a photoperiodically entrained circannual clock? J Pineal Res. 1994;17:151-163.

25. Monecke S, Sage-Ciocca D, Wollnik F, et al. Photoperiod can entrain circannual rhythms in pinealectomizedEuropean hamsters. $J$ Biol Rhythms. 2013;28:278-90.

26. Lincoln GA, Clarke IJ, Hut RA, et al. Characterizing a Mammalian circannual pacemaker. Science. 2006;314:1941-1944.

27. Dardente H. Melatonin-dependent timing of seasonal reproduction by the pars tuberalis: pivotal roles for long daylengths and thyroid hormones. J Neuroendocrinol. 2012;24:249-266.

28. Gwinner E. Circannual Rhythms. Berlin: Springer-Verlag; 1986.

29. Gwinner E, Dittami J. Endogenous reproductive rhythms in a tropical bird. Science. 1990;249:906-908.

30. Hoffmann $\mathrm{K}$, Illnerova $\mathrm{H}$, Vanecek J. Change in duration of the nighttime melatonin peak may be a signal driving photoperiodic responses in the Djungarian hamster (Phodopus sungorus). Neurosci Lett. 1986;67:68-72.

31. Robinson JE, Karsch FJ. Photoperiodic history and a changing melatonin pattern daylength. J Reprod Fertil. 1987;80:159-165.

32. Stokkan K-A, Tyler NJC, Reiter RJ. The pineal gland signals autumn to reindeer (Rangifer tarandus tarandus) exposed to the continuous daylight of the Arctic summer. Can J Zool. 1994;72:904-909.

33. Reierth E, Van't Hof TJ, Stokkan K-A. Seasonal and daily variations in plasma melatonin in the high-arctic svalbard ptarmigan (Lagopus mutus hyperboreus). J Biol Rhythms. 1999;14:314-319.

34. Stokkan K-A, van Oort BEH, Tyler NJC, et al. Adaptations for life in the Arctic: evidence that melatonin rhythms in reindeer are not driven by a Circadian oscillator but remain acutely sensitive to environmental photoperiod. J Pineal Res. 2007;43:289-293.

35. Strand JET, Aarseth JJ, Hanebrekke TL, et al. Keeping track of time under ice and snow in a sub-arctic lake: plasma melatonin rhythms in Arctic charr overwintering under natural conditions. J Pineal Res. 2008;44:227-233.

36. Stetson MH, Elliott JA, Goldman BD. Maternal transfer of photoperiodic information influences the photoperiodic response of prepubertal Djungarian hamsters (Phodopus sungorus sungorus). Biol Reprod. 1986;34:664-669.

37. Foster DL. Mechanism for delay of first ovulation in lambs born in the wrong season (fall). Biol Reprod. 1981;25:85-92.

38. Ebling FJP, Wood RI, Suttie JM, et al. Prenatal photoperiod influences neonatal prolactin secretion in sheep. Endocrinology. 1989;125:384-391.

39. Horton $\mathrm{TH}$, Stetson MH. Maternal transfer of photoperiodic information in rodents. Anim Reprod Sci. 1992;30:29-44.

40. Sáenz de Miera C, Bothorel B, Jaeger C, et al. Maternal photoperiod programs hypothalamic thyroid status via the fetal pituitary gland. Proc Natl Acad Sci USA. 2017;114:8408-8413.

41. Wood SH, Christian HC, Miedzinska K, et al. Binary switching of calendar cells in the pituitary defines the phase of the circannual cycle in mammals. Curr Biol. 2015;25:2652-2662.

42. Sáenz de Miera C. Maternal photoperiodic programming enlightens the internal regulation of thyroid-hormone deiodinases in tanycytes. J Neuroendocrinol. 2019;31:e12679.

43. Morgan PJ, Barrett P, Howell HE, et al. Melatonin receptors: Iocalization, molecular pharmacology and physiological significance. Neurochem Int. 1994;24:101-146.

44. Klosen P, Bienvenu C, Demarteau O, et al. The mt1 melatonin receptor and RORbeta receptor are co-localized in specific TSHimmunoreactive cells in the pars tuberalis of the rat pituitary. $J$ Histochem Cytochem. 2002;50:1647-1657.

45. Dardente $\mathrm{H}$, Klosen $\mathrm{P}$, Pévet $\mathrm{P}$, et al. MT1 melatonin receptor mRNA expressing cells in the pars tuberalis of the European hamster: effect of photoperiod. J Neuroendocrinol. 2003;15:778-786.

46. Johnston JD, Klosen P, Barrett P, et al. Regulation of MT melatonin receptor expression in the foetal rat pituitary. J Neuroendocrinol. 2006;18:50-56.

47. Lincoln GA. Neuroendocrine regulation of seasonal gonadotrophin and prolactin rhythms: lessons from the Soay ram model. Reproduction. 2002;59:131-147.

48. Curlewis JD. Seasonal prolactin secretion and its role in seasonal reproduction: a review. Reprod Fertil Dev. 1992;4:1-23.

49. Lincoln GA, Clarke IJ. Photoperiodically-induced cycles in the secretion of prolactin in hypothalamopituitary disconnected rams-evidence for translation of the melatonin signal in the pituitary-gland. J Neuroendocrinol. 1994;6:251-260.

50. Morgan PJ, Webster CA, Mercer JG, et al. The ovine pars tuberalis secretes a factor(s) that regulates gene expression in both lactotropic and nonlactotropic pituitary cells. Endocrinology. 1996;137:4018-4026. 
51. Stirland JA, Johnston JD, Cagampang FR, et al. Photoperiodic regulation of prolactin gene expression in the Syrian hamster by a pars tuberalis-derived factor. J Neuroendocrinol. 2001;13:147-157.

52. Morgan PJ, Williams LM. The pars tuberalis of the pituitary: a gateway for neuroendocrine output. Rev Reprod. 1996;1:153-161.

53. Hazlerigg DG, Gonzalez-Brito A, Lawson W, et al. Prolonged exposure to melatonin leads to time-dependent sensitization of adenylate cyclase and down-regulates melatonin receptors in pars tuberalis cells from ovine pituitary. Endocrinology. 1993;132:285-292.

54. Dardente H. Does a melatonin-dependent Circadian oscillator in the pars tuberalis drive prolactin seasonal rhythmicity? $J$ Neuroendocrinol. 2007;19:657-666.

55. Dupré SM, Burt DW, Talbot R, et al. Identification of melatoninregulated genes in the ovine pituitary pars tuberalis, a target site for seasonal hormone control. Endocrinology. 2008;149:5527-5539.

56. Fustin J, Dardente H, Wagner GC, et al. Egr1 involvement in evening gene regulation by melatonin. FASEB J. 2009;23:764-773.

57. Unfried C, Ansari N, Yasuo S, et al. Impact of melatonin and molecular clockwork components on the expression of thyrotropin beta-chain (Tshb) and the Tsh receptor in the mouse pars tuberalis. Endocrinology. 2009;150:4653-4662.

58. West A, Dupré SM, Yu L, et al. Npas4 is activated by melatonin, and drives the clock gene Cry1 in the ovine pars tuberalis. Mol Endocrinol. 2013;27:979-989.

59. Ray KP, Wallis M. Actions of dopamine on prolactin secretion and cyclic AMP metabolism in ovine pituitary cells. Mol Cell Endocrinol. 1982;27:139-155.

60. Ben-Jonathan N. Dopamine: a prolactin-inhibiting hormone. Endocr Rev. 1985;6:564-589.

61. Lincoln GA, Clarke IJ. Evidence that melatonin acts in the pituitary gland through a dopamine-independent mechanism to mediate effects of daylength on the secretion of prolactin in the Ram. $J$ Neuroendocrinol. 1995;7:637-643.

62. Bibb JA. Decoding dopamine signaling. Cell. 2005;122:153-155.

63. Lomet $\mathrm{D}$, Cognié J, Chesneau $\mathrm{D}$, et al. The impact of thyroid hormone in seasonal breeding has a restricted transcriptional signature. Cell Mol Life Sci. 2018;75:905-919.

64. Curlewis JD, Clarke IJ, McNeilly AS. Dopamine D1 receptor analogues act centrally to stimulate prolactin secretion in ewes. $J$ Endocrinol. 1993;137:457-464.

65. Södersten E, Feyder M, Lerdrup M, et al. Dopamine signaling leads to loss of polycomb repression and aberrant gene activation in experimental parkinsonism. PLoS Genet. 2014;10:e1004574.

66. Freeman ME, Kanyicska B, Lerant A, et al. Prolactin: structure, function, and regulation of secretion. Physiol Rev. 2000;80:1523-1631.

67. Dupré SM, Miedzinska K, Duval CV, et al. Identification of Eya3 and TAC1 as long-day signals in the sheep pituitary. Curr Biol. 2010;20:829-835.

68. Yasuo S, Korf H-W. The hypophysial pars tuberalis transduces photoperiodic signals via multiple pathways and messenger molecules. Gen Comp Endocrinol. 2011;172:15-22.

69. Korf H-W. Signaling pathways to and from the hypophysial pars tuberalis, an important center for the control of seasonal rhythms. Gen Comp Endocrinol. 2018;258:236-243.

70. Yasuo S, Fischer C, Bojunga J, et al. 2-Arachidonoyl glycerol sensitizes the pars distalis and enhances forskolin-stimulated prolactin secretion in Syrian hamsters. Chronobiol Int. 2014:31:337-342.

71. Wood SH. How can a binary switch within the pars tuberalis control seasonal timing of reproduction? J Endocrinol. 2018;239:R13-R25.

72. Hazlerigg DG, Lincoln GA. Hypothesis: cyclical histogenesis is the basis of circannual timing. J Biol Rhythms. 2011;26:471-485.

73. Migaud M, Batailler M, Pillon D, et al. Seasonal changes in cell proliferation in the adult sheep brain and pars tuberalis. $J$ Biol Rhythms. 2011:26:486-496.
74. Hazlerigg DG, Wyse CA, Dardente $\mathrm{H}$, et al. Photoperiodic variation in CD45-positive cells and cell proliferation in the mediobasal hypothalamus of the Soay sheep. Chronobiol Int. 2013;30:548-558.

75. Snitow ME, Li S, Morley MP, et al. Ezh2 represses the basal cell lineage during lung endoderm development. Development. 2015;142:108-117.

76. Hwang WW, Salinas RD, Siu JJ, et al. Distinct and separable roles for EZH2 in neurogenic astroglia. Elife. 2014;3:e02439.

77. Dardente H, Wyse CA, Birnie MJ, etal. A molecular switch for photoperiod responsiveness in mammals. Curr Biol. 2010;20:2193-2198.

78. Masumoto K, Ukai-Tadenuma M, Kasukawa T, et al. Acute induction of Eya3 by late-night light stimulation triggers TSH beta expression in photoperiodism. Curr Biol. 2010;20:2199-2206.

79. Sáenz de Miera C, Hanon EA, Dardente H, et al. Circannual variation in thyroid hormone deiodinases in a short-day breeder. $J$ Neuroendocrinol. 2013;25:412-421.

80. Sáenz de Miera C, Sage-Ciocca D, Simonneaux V, et al. Melatoninindependent photoperiodic entrainment of the circannual TSH rhythm in the pars tuberalis of the European hamster. J Biol Rhythms. 2018;33:302-317.

81. Hazlerigg D, Blix AS, Stokkan K-A. Waiting for the sun: the circannual program of reindeer is delayed by the recurrence of rhythmical melatonin secretion after the arctic night. J Exp Biol. 2017;220:163741.

82. Pittendrigh CS. Circadian surfaces and the diversity of possible roles of Circadian organization in photoperiodic induction. Proc Natl Acad Sci USA. 1972;69:2734-2737.

83. Dawson A, King VMV, Bentley GE, et al. Photoperiodic control of seasonality in birds. J Biol Rhythms. 2001;16:365-380.

84. Lincoln GA, Messager S, Andersson $\mathrm{H}$, et al. Temporal expression of seven clock genes in the suprachiasmatic nucleus and the pars tuberalis of the sheep: evidence for an internal coincidence timer. Proc Natl Acad Sci USA. 2002;99:13890-13895.

85. Yoshimura T, Yasuo S, Watanabe M, et al. Light-induced hormone conversion of T4 to T3 regulates photoperiodic response of gonads in birds. Nature. 2003;426:178-181.

86. Nakao N, Ono H, Yamamura T, et al. Thyrotrophin in the pars tuberalis triggers photoperiodic response. Nature. 2008;452:317-323.

87. Hanon EA, Lincoln GA, Fustin JM, et al. Ancestral TSH mechanism signals summer in a photoperiodic mammal. Curr Biol. 2008;18:30-32.

88. Ikegami $\mathrm{K}$, Liao $\mathrm{X}$, Hoshino $\mathrm{Y}$, et al. Tissue-specific posttranslational modification allows functional targeting of thyrotropin. Cell Rep. 2014;9:1-9.

89. Bianco AC, Salvatore D, Gereben B, et al. Biochemistry, cellular and molecular biology, and physiological roles of the iodothyronine selenodeiodinases. Endocr Rev. 2002;23:38-89.

90. Klosen P, Sébert ME, Rasri K, et al. TSH restores a summer phenotype in photoinhibited mammals via the RF-amides RFRP3 and kisspeptin. FASEB J. 2013;27:2677-2686.

91. Ross AW, Helfer G, Russell L, et al. Thyroid hormone signalling genes are regulated by photoperiod in the hypothalamus of F344 rats. PLoS ONE. 2011;6:e21351.

92. Ono $\mathrm{H}$, Hoshino $\mathrm{Y}$, Yasuo $\mathrm{S}$, et al. Involvement of thyrotropin in photoperiodic signal transduction in mice. Proc Natl Acad Sci USA. 2008;105:18238-18242.

93. Revel FG, Saboureau M, Pévet P, et al. Melatonin regulates type 2 deiodinase gene expression in the Syrian hamster. Endocrinology. 2006;147:4680-4687.

94. Barrett P, Ebling FJP, Schuhler S, et al. Hypothalamic thyroid hormone catabolism acts as a gatekeeper for the seasonal control of body weight and reproduction. Endocrinology. 2007;148:3608-3617.

95. Helfer G, Ross AW, Morgan PJ. Neuromedin U partly mimics thyroid-stimulating hormone and triggers $\mathrm{Wnt} / ß$-catenin signalling 
in the photoperiodic response of F344 rats. J Neuroendocrinol. 2013;25:1264-1272.

96. Petri I, Diedrich V, Wilson D, et al. Orchestration of gene expression across the seasons: hypothalamic gene expression in natural photoperiod throughout the year in the Siberian hamster. Sci Rep. 2016;6:29689.

97. Milesi S, Simonneaux V, Klosen P. Downregulation of deiodinase 3 is the earliest event in photoperiodic and photorefractory activation of the gonadotropic axis in seasonal hamsters. Sci Rep. 2017;7:1-10.

98. Graham ES, Turnbull $Y$, Fotheringham P, et al. Neuromedin $U$ and neuromedin $U$ receptor-2 expression in the mouse and rat hypothalamus: effects of nutritional status. J Neurochem. 2003;87:1165-1173.

99. Lewis JE, Ebling FJP. Tanycytes as regulators of seasonal cycles in neuroendocrine function. Front Neurol. 2017;8:1-7.

100. Rodríguez EM, Blázquez JL, Pastor FE, et al. Hypothalamic tanycytes: a key component of brain-endocrine interaction. Int Rev Cytol. 2005;247:89-164.

101. Prevot V, Dehouck B, Sharif A, et al. The versatile tanycyte: a hypothalamic integrator of reproduction and energy metabolism. Endocr Rev. 2018;39:336-368.

102. Benford $\mathrm{H}$, Bolborea $\mathrm{M}$, Pollatzek $\mathrm{E}$, et al. A sweet taste receptordependent mechanism of glucosensing in hypothalamic tanycytes. Glia. 2017;65:773-789.

103. Lazutkaite G, Soldà A, Lossow K, et al. Amino acid sensing in hypothalamic tanycytes via umami taste receptors. Mol Metab. 2017;6:1480-1492.

104. Bolborea M, Dale N. Hypothalamic tanycytes: potential roles in the control of feeding and energy balance. Trends Neurosci. 2013;36:91-100.

105. Goodman T, Hajihosseini MK. Hypothalamic tanycytes-masters and servants of metabolic, neuroendocrine, and neurogenic functions. Front Neurosci. 2015;9:1-9.

106. Chen R, Wu X, Jiang L, et al. Single-cell RNA-Seq reveals hypothalamic cell diversity. Cell Rep. 2017;18:3227-3241.

107. Campbell JN, Macosko EZ, Fenselau H, et al. A molecular census of arcuate hypothalamus and median eminence cell types. Nat Neurosci. 2017;20:484-496.

108. Romanov RA, Zeisel A, Bakker J, et al. Molecular interrogation of hypothalamic organization reveals distinct dopamine neuronal subtypes. Nat Neurosci. 2017;20:176-188.

109. Dardente H, Lomet D. Photoperiod and thyroid hormone regulate expression of I-dopachrome tautomerase (Dct), a melanocyte stem-cell marker, in tanycytes of the ovine hypothalamus. $J$ Neuroendocrinol. 2018;30:1-10.

110. Clark SD, Duangdao DM, Schulz S, et al. Anatomical characterization of the neuropeptide $\mathrm{S}$ system in the mouse brain by in situ hybridization and immunohistochemistry. J Comp Neurol. 2011:519:1867-1893.

111. Pulkkinen V, Ezer S, Sundman L, et al. Neuropeptide S receptor 1 (NPSR1) activates cancer-related pathways and is widely expressed in neuroendocrine tumors. Virchows Arch. 2014;465:173-183.

112. Ingham PW, Mcmahon AP. Hedgehog signaling in animal development: paradigms and principles. Genes Dev. 2001;15:3059-3087.

113. Jiao Z, Zhang ZG, Hornyak TJ, et al. Dopachrome tautomerase (Dct) regulates neural progenitor cell proliferation. Dev Biol. 2006;296:396-408.

114. Nishimura EK, Jordan SA, Oshima H, et al. Dominant role of the niche in melanocyte stem-cel fate determination. Nature. 2002;416:854-860.

115. Yamamura T, Hirunagi K, Ebihara S, et al. Seasonal morphological changes in the neuro-glial interaction between gonadotropin-releasing hormone nerve terminals and glial endfeet in Japanese quail. Endocrinology. 2004;145:4264-4267.
116. Prevot V, Croix D, Bouret S, et al. Definitive evidence for the existence of morphological plasticity in the external zone of the median eminence during the rat estrous cycle: implication of neuro-glio-endothelial interactions in gonadotropin-releasing hormone release. Neuroscience. 1999;94:809-819.

117. Kameda Y, Arai Y, Nishimaki T. Ultrastructural localization of vimentin immunoreactivity and gene expression in tanycytes and their alterations in hamsters kept under different photoperiods. Cell Tissue Res. 2003;314:251-262.

118. Bolborea M, Laran-Chich M-P, Rasri K, et al. Melatonin controls photoperiodic changes in tanycyte vimentin and neural cell adhesion molecule expression in the Djungarian hamster (Phodopus sungorus). Endocrinology. 2011;152:3871-3883.

119. Butruille L, Batailler M, Mazur D, et al. Seasonal reorganization of hypothalamic neurogenic niche in adult sheep. Brain Struct Funct. 2018;223:91-109.

120. Stevenson TJ, Prendergast BJ. Reversible DNA methylation regulates seasonal photoperiodic time measurement. Proc Natl Acad Sci USA. 2013;110:16651-16656.

121. Stevenson TJ. Epigenetic regulation of biological rhythms: an evolutionary ancient molecular timer. Trends Genet. 2017;34:90-100.

122. Stoney PN, Rodrigues D, Helfer G, et al. A seasonal switch in histone deacetylase gene expression in the hypothalamus and their capacity to modulate nuclear signaling pathways. Brain Behav Immun. 2017;61:340-352.

123. Xu Y, Tamamaki N, Noda T, et al. Neurogenesis in the ependymal layer of the adult rat 3rd ventricle. Exp Neurol. 2005;192:251-264.

124. Kokoeva MV, Yin H, Flier JS. Neurogenesis in the hypothalamus of adult mice: potential role in energy balance. Science. 2005;310:679-683.

125. Batailler M, Derouet L, Butruille L, et al. Sensitivity to the photoperiod and potential migratory features of neuroblasts in the adult sheep hypothalamus. Brain Struct Funct. 2016;221: 3301-3314.

126. Robins SC, Stewart I, McNay DE, et al. $\alpha$-Tanycytes of the adult hypothalamic third ventricle include distinct populations of FGFresponsive neural progenitors. Nat Commun. 2013;4:2049.

127. Lee DA, Bedont JL, Pak T, et al. Tanycytes of the hypothalamic median eminence form a diet-responsive neurogenic niche. Nat Neurosci. 2012;15:700-702.

128. Haan N, Goodman T, Najdi-Samiei A, et al. Fgf10-expressing tanycytes add new neurons to the appetite/energy-balance regulating centers of the postnatal and adult hypothalamus. J Neurosci. 2013;33:6170-6180

129. Batailler M, Chesneau D, Derouet $L$, et al. Pineal-dependent increase of hypothalamic neurogenesis contributes to the timing of seasonal reproduction in sheep. Sci Rep. 2018;8:1-13.

130. Huang LY, Devries GJ, Bittman EL. Bromodeoxyuridine labeling in the brain of a seasonally breeding mammal. J Neurobiol. 1998;36:410-420.

131. Shearer KD, Stoney PN, Morgan PJ, et al. A vitamin for the brain. Trends Neurosci. 2012;35:733-741.

132. Chaker Z, George C, Petrovska M, et al. Hypothalamic neurogenesis persists in the aging brain and is controlled by energy-sensing IGF-I pathway. Neurobiol Aging. 2016;41:64-72.

133. Helfer G, Ross AW, Russell L, et al. Photoperiod regulates vitamin $\mathrm{A}$ and $\mathrm{Wnt} / \beta$-catenin signaling in F344 rats. Endocrinology. 2012;153:815-824

134. Ikegami K, Yoshimura T. Comparative analysis reveals the underlying mechanism of vertebrate seasonal reproduction. Gen Comp Endocrinol. 2016;227:64-68.

135. Herwig A, de Vries EM, Bolborea M, et al. Hypothalamic ventricular ependymal thyroid hormone deiodinases are an important element of circannual timing in the Siberian hamster (Phodopus sungorus). PLoS ONE. 2013;8:e62003. 
136. Hazlerigg D, Lomet D, Lincoln G, et al. Neuroendocrine correlates of the critical day length response in the Soay sheep. $J$ Neuroendocrinol. 2018;30:e12631.

137. Murphy M, Jethwa PH, Warner A, et al. Effects of manipulating hypothalamic triiodothyronine concentrations on seasonal body weight and torpor cycles in Siberian hamsters. Endocrinology. 2012;153:101-112.

138. Anderson GM, Hardy SL, Valent M, et al. Evidence that thyroid hormones act in the ventromedial preoptic area and the premammillary region of the brain to allow the termination of the breeding season in the ewe. Endocrinology. 2003;144:2892-2901.

139. Herwig A, Campbell G, Mayer C-D, et al. A thyroid hormone challenge in hypothyroid rats identifies T3 regulated genes in the hypothalamus and in models with altered energy balance and glucose homeostasis. Thyroid. 2014;24:1575-1593.

140. Ross AW, Webster CA, Mercer JG, et al. Photoperiodic regulation of hypothalamic retinoid signaling: association of retinoid $X$ receptor gamma with body weight. Endocrinology. 2004;145:13-20.

141. Shearer KD, Goodman TH, Ross AW, et al. Photoperiodic regulation of retinoic acid signaling in the hypothalamus. J Neurochem. 2010;112:246-257.

142. Boucsein A, Benzler J, Hempp C, et al. Photoperiodic and diurnal regulation of WNT signaling in the arcuate nucleus of the female Djungarian hamster, Phodopus sungorus. Endocrinology. 2016;157:799-809.

143. Ebling FJP, Barrett P. The regulation of seasonal changes in food intake and body weight. J Neuroendocrinol. 2008;20:827-833.

144. Talbi R, Klosen P, Laran-Chich MP, et al. Coordinated seasonal regulation of metabolic and reproductive hypothalamic peptides in the desert jerboa. J Comp Neurol. 2016;524:3717-3728.

145. Talbi R, Laran-Chich MP, Magoul R, et al. Kisspeptin and RFRP-3 differentially regulate food intake and metabolic neuropeptides in the female desert jerboa. Sci Rep. 2016;6:1-10.

146. Clarke IJ, Scott CJ, Rao A, et al. Seasonal changes in the expression of neuropeptide $Y$ and pro-opiomelanocortin mRNA in the arcuate nucleus of the ovariectomized ewe: relationship to the seasonal appetite and breeding cycles. J Neuroendocrinol. 2000;12:1105-1111.

147. Clarke IJ, Rao A, Chilliard Y, et al. Photoperiod effects on gene expression for hypothalamic appetite-regulating peptides and food intake in the ram. Am J Physiol Regul Integr Comp Physiol. 2003;284:R101-R115.

148. Barrell GK, Ridgway MJ, Wellby M, et al. Expression of regulatory neuropeptides in the hypothalamus of red deer (Cervus elaphus) reveals anomalous relationships in the seasonal control of appetite and reproduction. Gen Comp Endocrinol. 2016;229:1-7.

149. Reddy AB, Cronin AS, Ford $H$, et al. Seasonal regulation of food intake and body weight in the male Siberian hamster: studies of hypothalamic orexin (hypocretin), neuropeptide Y (NPY) and proopiomelanocortin (POMC). Eur J Neurosci. 1999;11:3255-3264.

150. Rousseau K, Atcha Z, Cagampang FRA, et al. Photoperiodic regulation of leptin resistance in the seasonally breeding Siberian hamster (Phodopus sungorus). Endocrinology. 2002;143:3083-3095.

151. Mercer JG, Moar KM, Ross AW, et al. Photoperiod regulates arcuate nucleus POMC, AGRP, and leptin receptor mRNA in Siberian hamster hypothalamus. Am J Physiol Regul Integr Comp Physiol. 2000;278:R271-R281.

152. van den Pol AN, Decavel C, Levi A, et al. Hypothalamic expression of a novel gene product, VGF: immunocytochemical analysis. J Neurosci. 1989;9:4122-4137.

153. Barrett $P$, Ross AW, Balik A, et al. Photoperiodic regulation of histamine $\mathrm{H} 3$ receptor and VGF messenger ribonucleic acid in the arcuate nucleus of the Siberian hamster. Endocrinology. 2005;146:1930-1939.

154. Lewis JE, Brameld JM, Hill P, et al. Thyroid hormone and vitamin $D$ regulate VGF expression and promoter activity. J Mol Endocrinol. 2016:56:123-134
155. Lewis JE, Brameld JM, Hill P, et al. Hypothalamic over-expression of VGF in the Siberian hamster increases energy expenditure and reduces body weight gain. PLoS ONE. 2017;12:1-14.

156. Jethwa PH, Warner A, Nilaweera KN, et al. VGF-derived peptide, TLQP-21, regulates food intake and body weight in Siberian hamsters. Endocrinology. 2007;148:4044-4055.

157. Dumbell RA, Scherbarth F, Diedrich V, et al. Somatostatin agonist pasireotide promotes a physiological state resembling short-day acclimation in the photoperiodic male Siberian hamster (Phodopus sungorus). J Neuroendocrinol. 2015;27:588-599.

158. Scherbarth F, Diedrich V, Dumbell RA, et al. Somatostatin receptor activation is involved in the control of daily torpor in a seasonal mammal. Am J Physiol Regul Integr Comp Physiol. 2015;50:668-674.

159. Revel FG, Saboureau M, Masson-Pévet M, et al. Kisspeptin mediates the photoperiodic control of reproduction in hamsters. Curr Biol. 2006;16:1730-1735.

160. Smith JT, Dungan HM, Stoll EA, et al. Differential regulation of KiSS-1 mRNA expression by sex steroids in the brain of the male mouse. Endocrinology. 2005;146:2976-2984.

161. Ansel L, Bolborea M, Bentsen AH, et al. Differential regulation of Kiss1 expression by melatonin and gonadal hormones in male and female Syrian hamsters. J Biol Rhythms. 2010;25:81-91.

162. Revel FG, Saboureau M, Pévet $P$, et al. RFamide-related peptide gene is a melatonin-driven photoperiodic gene. Endocrinology. 2008:149:902-912.

163. Ubuka T, Inoue K, Fukuda $\mathrm{Y}$, et al. Identification, expression, and physiological functions of Siberian hamster gonadotropin-inhibitory hormone. Endocrinology. 2012;153:373-385.

164. Rasri-Klosen K, Simonneaux V, Klosen P. Differential response patterns of kisspeptin and RFRP to photoperiod and sex steroid feedback in the Djungarian hamster (Phodopus sungorus). $J$ Neuroendocrinol. 2017;3:1-13.

165. Angelopoulou E, Quignon C, Kriegsfeld LJ, et al. Functional implications of RFRP-3 in the central control of daily and seasonal rhythms in reproduction. Front Endocrinol. 2019;10:183.

166. Beltramo M, Dardente H, Cayla X, et al. Cellular mechanisms and integrative timing of neuroendocrine control of $\mathrm{GnRH}$ secretion by kisspeptin. Mol Cell Endocrinol. 2014;382:387-399.

167. Tsutsui K, Ubuka T. How to contribute to the progress of neuroendocrinology: discovery of $\mathrm{GnIH}$ and progress of $\mathrm{GnIH}$ research. Front Endocrinol. 2018;9:1-16.

168. Simonneaux V. A kiss to drive rhythms in reproduction. Eur $J$ Neurosci. 2018https://doi.org/10.1111/ejn.14287

169. Herbison AE. The gonadotropin-releasing hormone pulse generator. Endocrinology. 2018;159:3723-3736.

170. Kriegsfeld LJ. Driving reproduction: RFamide peptides behind the wheel. Horm Behav. 2006:50:655-666.

171. Tsutsui K, Bentley GE, Bedecarrats G, et al. Gonadotropin-inhibitory hormone $(\mathrm{GnlH})$ and its control of central and peripheral reproductive function. Front Neuroendocrinol. 2010;31:284-295.

172. Ancel C, Bentsen AH, Sébert ME, et al. Stimulatory effect of RFRP-3 on the gonadotrophic axis in the male Syrian hamster: the exception proves the rule. Endocrinology. 2012;153:1352-1363.

173. Henningsen JB, Ancel C, Mikkelsen JD, et al. Roles of RFRP-3 in the daily and seasonal regulation of reproductive activity in female Syrian hamsters. Endocrinology. 2017;158:652-663.

174. León S, García-Galiano D, Ruiz-Pino F, et al. Physiological roles of gonadotropin-inhibitory hormone signaling in the control of mammalian reproductive axis: studies in the NPFF1 receptor null mouse. Endocrinology. 2014;155:2953-2965.

175. Decourt C, Anger K, Robert V, et al. No evidence that RFamide related peptide 3 directly modulates $\mathrm{LH}$ secretion in the ewe. Endocrinology. 2016;157:1566-1575.

176. Clarke IJ, Sari IP, Qi Y, et al. Potent action of RFamide-related peptide-3 on pituitary gonadotropes indicative of a 
hypophysiotropic role in the negative regulation of gonadotropin secretion. Endocrinology. 2008;149:5811-5821.

177. Thorson JF, Prezotto LD, Cardoso RC, et al. Hypothalamic Distribution, Adenohypophyseal Receptor Expression, and Ligand Functionality of RFamide-Related Peptide 3 in the Mare During the Breeding and Nonbreeding Seasons. Biol Reprod. 2014;90. Article 28.

178. Clarke IJ, Smith JT, Henry BA, et al. Gonadotropin-inhibitory hormone is a hypothalamic peptide that provides a molecular switch between reproduction and feeding. Neuroendocrinology. 2012;95:305-316.

179. Jaroslawska J, Chabowska-Kita A, Kaczmarek MM, et al. Npvf: hypothalamic biomarker of ambient temperature independent of nutritional status. PLoS Genet. 2015;11:1-23.

180. Henson JR, Carter SN, Freeman DA. Exogenous T3 elicits long day-like alterations in testis size and the RFamides Kisspeptin and gonadotropin-inhibitory hormone in short-day Siberian hamsters. J Biol Rhythms. 2013;28:193-200.

181. Cravo RM, Margatho LO, Osborne-Lawrence S, et al. Characterization of Kiss1 neurons using transgenic mouse models. Neuroscience. 2011;173:37-56.

182. Qiu J, Rivera HM, Bosch MA, et al. Estrogenic-dependent glutamatergic neurotransmission from kisspeptin neurons governs feeding circuits in females. Elife. 2018;7:1-34.

183. Merkley CM, Coolen LM, Goodman RL, et al. Evidence for changes in numbers of synaptic inputs onto KNDy and GnRH neurones during the preovulatory LH surge in the ewe. J Neuroendocrinol. 2015;27:624-635.

184. Poling MC, Kim J, Dhamija S, et al. Development, sex steroid regulation, and phenotypic characterization of RFamide-related peptide (Rfrp) gene expression and RFamide receptors in the mouse hypothalamus. Endocrinology. 2012;153:1827-1840.

185. Weems PW, Goodman RL, Lehman MN. Neural mechanisms controlling seasonal reproduction: principles derived from the sheep model and its comparison with hamsters. Front Neuroendocrinol. 2015;37:43-51.

186. Moore AM, Coolen LM, Porter DT, et al. KNDy cells revisited. Endocrinology. 2018;159:3219-3234.

187. Legan SJ, Karsch FJ, Foster DL. The endocrine control of seasonal reproductive function in the ewe: a marked change in response to the negative feedback action of estradiol on luteinizing hormone secretion. Endocrinology. 1977;101:818-824.

188. Goodman RL, Bittman EL, Foster DL, et al. Alterations in the control of luteinizing hormone pulse frequency underlie the seasonal variation in estradiol negative feedback in the ewe. Biol Reprod. 1982;27:580-589.
189. Ginther OJ, Gastal EL, Gastal MO, et al. Seasonal influence on equine follicle dynamics. Anim Reprod. 2004;1:31-44.

190. Robinson JE, Follett BK. Photoperiodism in Japanese quail: the termination of seasonal breeding by photorefractoriness. Proc $R$ Soc Lond B Biol Sci. 1982;215:95-116.

191. Davis GJ, Meyer RK. Seasonal Variation in LH and FSH of bilaterally castrated snowshoe hares. Gen Comp Endocrinol. 1973;20:61-68.

192. Smith JT. Sex steroid regulation of kisspeptin circuits. In: Kauffman AS, Smith JT, eds. Kisspeptin Signaling in Reproductive Biology. New York, NY: Springer; 2013:275-295.

193. Fitzgerald KT. The structure and function of the pars tuberalis of the vertebrate adenohypophysis. Gen Comp Endocrinol. 1979;37:383-399.

194. Nakane $\mathrm{Y}$, Ikegami K, ligo $\mathrm{M}$, et al. The saccus vasculosus of fish is a sensor of seasonal changes in day length. Nat Commun. 2013;4:2108

195. Fleming MS, Maugars G, Lafont A-G, et al. Functional divergence of thyrotropin beta-subunit paralogs gives new insights into salmon smoltification metamorphosis. Sci Rep. 2019;9:1-15.

196. Lorgen $M$, Casadei $E$, Król $E$, et al. Functional divergence of type 2 deiodinase paralogs in the Atlantic salmon. Curr Biol. 2015;25:936-941.

197. O'Brien CS, Bourdo R, Bradshaw WE, et al. Conservation of the photoperiodic neuroendocrine axis among vertebrates: evidence from the teleost fish, Gasterosteus aculeatus. Gen Comp Endocrinol. 2012;178:19-27.

198. Kitano J, Lema SC, Luckenbach JA, et al. Adaptive divergence in the thyroid hormone signaling pathway in the stickleback radiation. Curr Biol. 2010;20:2124-2130.

199. Mure LS, Le HD, Benegiamo G, et al. Diurnal transcriptome atlas of a primate across major neural and peripheral tissues. Science. 2018;359:eaao0318.

200. Fan Z, Li W, Lee SR, et al. Efficient gene targeting in golden Syrian hamsters by the CRISPR/Cas9 system. PLoS ONE. 2014;9:e109755.

201. Hand LE, Saer BRC, Hui ST, et al. Induction of the metabolic regulator Txnip in fasting-induced and natural torpor. Endocrinology. 2013;154:2081-2091.

How to cite this article: Dardente H, Wood S, Ebling F, Sáenz de Miera C. An integrative view of mammalian seasonal neuroendocrinology. J Neuroendocrinol. 2019;31:e12729. https://doi.org/10.1111/jne.12729 